\title{
Effect of Contaminants on the Gas Holdup and Mixing in Internal Airlift Reactors Equipped with Microbubble Generator
}

\author{
Surya K. Pallapothu and Adel M. Al Taweel \\ Multiphase Mixing and Separations Research Laboratory, Department of Process Engineering and Applied Sciences, \\ Dalhousie University, Halifax, NS, Canada B3J 2X4 \\ Correspondence should be addressed to Adel M. Al Taweel, al.taweel@dal.ca
}

Received 6 June 2012; Accepted 27 August 2012

Academic Editor: Diego Gómez-Díaz

Copyright ( $) 2012$ S. K. Pallapothu and A. M. Al Taweel. This is an open access article distributed under the Creative Commons Attribution License, which permits unrestricted use, distribution, and reproduction in any medium, provided the original work is properly cited.

\begin{abstract}
The impact of contaminants on the gas holdup and mixing characteristics encountered in internal airlift reactors was investigated using a $200 \mathrm{~L}$ pilot scale unit equipped with a two-phase transonic sparger capable of generating microbubbles. Small dosages of a cationic surfactant ( $0-50 \mathrm{ppm}$ of sodium dodecyl sulfonate (SDS)) were used to simulate the coalescence-retarding effect encountered in most industrial streams and resulted in the formation of bubbles that varied in size between 280 and 1,900 $\mu \mathrm{m}$. Gas holdups as high as 0.14 were achieved in the riser under homogeneous flow regime when slowly coalescent systems were aerated at the relatively low superficial velocity of $0.02 \mathrm{~ms}^{-1}$, whereas liquid circulation velocities as high as $1.3 \mathrm{~ms}^{-1}$ were achieved in conjunction with rapidly coalescent systems at the same superficial velocity. This excellent hydrodynamic performance represents a 5-fold improvement in the riser gas holdup and up to 8-fold enhancement in the liquid circulation velocity and is expected to yield good mixing and mass transfer performance at low energy dissipation rates.
\end{abstract}

\section{Introduction}

Virtually all process streams encountered in the chemi$\mathrm{cal} / \mathrm{biochemical} /$ process industries contain varying concentrations of amphiphilic materials (such as alcohols, surfactants, organic acids, electrolytes, amines, glycols, proteins, phenols, and finely divided particles) that are introduced as reactants, as impurities in the feed and recycle streams, or formed as products and/or byproducts. Although it is well known that the presence of such materials can significantly impact gas/liquid contacting operations, the manner and magnitude by which these changes take place are still controversial. Consequently, much of the practices prevalent today in gas/liquid contacting are based on information and observations obtained using relatively clean systems where the equilibrium between bubble breakage and coalescence is quickly approached, a situation that does not truly reflect what is happening in most industrial situations. The fact that there is no definite agreement on even some basic fundamental concepts resulted in gas/liquid contacting operations not achieving their full potential when applied to slowly coalescent industrial streams. For example, whereas some investigators report that the volumetric mass transfer coefficient is positively impacted by the presence of surfactants, others report a negative impact.

A significant part of the factors hampering the development of a systematic and comprehensive understanding of how contaminants impact gas/liquid contacting in industrial situations stems from the strong interaction between the various factors affecting it [1]. Consequently, the influence of the aforementioned contaminants on the specific interphase area of contact, $a$, and the liquid side mass transfer coefficient, $k_{L}$, could be significantly different. Although there is no clear understanding of the mechanisms by which amphiphilic materials impact $k_{L}$, there is a general recognition that it is adversely affected in the presence of amphiphilic materials [2-8] Means by which large interfacial area of contact can be generated between the phases are therefore promising avenues by which high $k_{L} a$ values can be achieved in industrial systems. This is usually achieved by increasing the energy input to the system, an approach that can adversely affect the energetic performance of gas 
liquid contacting operations. Industrial practice has however proven that large interfacial area of contact can be achieved without large energy expenditures by focusing energy dissipation within a small portion of the contactor's volume (whereby very small bubbles are formed) and relying on the coalescence retardation characteristic inherent to industrial streams in order to maintain relatively large interfacial area in other parts of the contactor $[9,10]$.

A similar situation exists in the case of bubble columns and airlift reactors (ALRs). As was shown by Bordel et al. [11], the assumption that the entire column is in dynamic equilibrium is in general not valid; furthermore, the column length it takes to approach a state of dynamic equilibrium between bubble breakage and coalescence in the column depends mainly on the difference between the initial mean bubble diameter and that achieved at equilibrium. Their results, as well as those obtained by many other computational fluid dynamics simulations of gas/liquid contacting in bubble columns $[12,13]$, show that this phenomenon is particularly significant in the case of homogeneous flow of slowly coalescent gas/liquid dispersions where the influence of the initial conditions that are dictated by the type and configuration of the sparger plays a more pronounced role [14-16].

Several investigators experimentally studied the impact of soluble organic amphiphilic compounds on gas liquid contacting in bubble columns with a particular emphasis on surfactants and alcohols $[5,7,9,15,17-19]$. On the other hand, most of the investigations involving ALR focused on alcohols $[7,16,19,20]$ while relatively few assessed the impact of surfactants [7, 21-23].

Several attempts were made to improve gas/liquid contacting in airlift reactors by using spargers capable of generating microbubbles [24-27] but the extent of mass transfer improvement achieved was somewhat limited. Bredwell and Worden explored the potential for using microbubbles to overcome mass transfer limitations in fermentation operations and achieved more than 6-fold increase in the value of $k_{L} a$ by replacing the stainless steel frit sparger by a microbubble generator. Although the power needed to drive the microbubble generator is very small $\left(0.01 \mathrm{~kW} / \mathrm{m}^{3}\right.$ of the fermentation capacity), the maximum mass transfer coefficient achieved was less than $0.025 \mathrm{~s}^{-1}$. In a similar fashion, significant improvement in the decomposition rate of organic compounds was achieved when ozone was dispersed in the form of microbubbles $[28,29]$, but the maximum volumetric mass transfer coefficient achieved in an improved version of their reactor was very low $\left(k_{L} a<0.002 \mathrm{~s}^{-1}\right)$ mainly because of the very small gas flow rates that could be handled using the microbubble generator investigated [25]. Likewise, the mass transfer rates achieved by Chu et al. [30] were relatively low $\left(k_{L} a<0.006 \mathrm{~s}^{-1}\right)$. One can therefore conclude that although the use of microbubbles represents a very promising avenue for increasing interphase mass transfer, it has been successfully used only in situations where the amount of gases to be transferred is relatively small (e.g., using ozone to disinfect water and oxidize small residual organic contaminants).
TABLE 1: Characteristics of the internal loop ALR.

\begin{tabular}{lcc}
\hline Characteristic & Scale & Units \\
\hline Reactor diameter & 0.3 & $\mathrm{~m}$ \\
Riser diameter & 0.23 & $\mathrm{~m}$ \\
Riser height & 2.3 & $\mathrm{~m}$ \\
Reactor height & 2.75 & $\mathrm{~m}$ \\
Gas separator diameter & 0.5 & $\mathrm{~m}$ \\
Bottom clearance & 0.2 & $\mathrm{~m}$ \\
Total reactor volume & 200 & $\mathrm{~L}$ \\
Riser volume & 95 & $\mathrm{~L}$ \\
Downcomer to riser area ratio & 1.2 & - \\
Separator to riser area ratio & 4.7 & - \\
Reactor height to diameter ratio & 9 & - \\
\hline
\end{tabular}

Attempts have been recently undertaken to overcome this barrier, and the potential for using microbubbles to enhance $\mathrm{CO}_{2}$ absorption/stripping was investigated by $\mathrm{Al}$ Mashhadani et al. [26] where a bubble cloud (with a Sauter mean diameter, $d_{32}$, of $550 \mu \mathrm{m}$ ) was generated using a two-chamber microporous ceramic diffuser with fluidic oscillation. The mass transfer coefficient obtained using the microbubbles generated by that device $\left(k_{L} a=0.0015 \mathrm{~s}^{-1}\right)$ was about $20 \%$ higher than that achieved using fine bubble spargers $\left(d_{32}=1,300 \mu \mathrm{m}\right)$ at the same gas flowrate. The main reason behind such limited volumetric mass transfer values is the relatively low throughputs that can be handled by such units; hence, many spargers will be needed in order to handle the large volumetric gas flow rates typically associated with such operation.

The objective of this study is to investigate the impact of using microbubbles on the hydrodynamic performance of airlift reactors using rapid and slowly coalescent systems that simulate what happens in industrial streams. The microbubble generator (sparger) tested is one that was developed to handle the relatively large gas flow rates needed in the oil and gas industry and can provide an additional process control parameter in the case of ALR by virtue of its ability to uninterruptedly change the size of bubbles generated.

\section{Experimental}

The effect surfactants have on the hydrodynamics of ALR was investigated using the experimental setup depicted in Figure 1. A $200 \mathrm{~L}$ pilot scale internal loop airlift reactor, the characteristics of which are given in Table 1, was used in an arrangement that could be operated in both batch and continuous modes. However, the batch operational mode (achieved by recirculating some of the liquid present in the reactor through the transonic sparger) was adopted throughout this investigation in order to simplify testing and shorten time requirements.

The geometric proportions used in the present investigation were commonly used in many previous investigators and found to result in adequate gas/liquid phase separation when conventional bubbles were used. However, the size of 


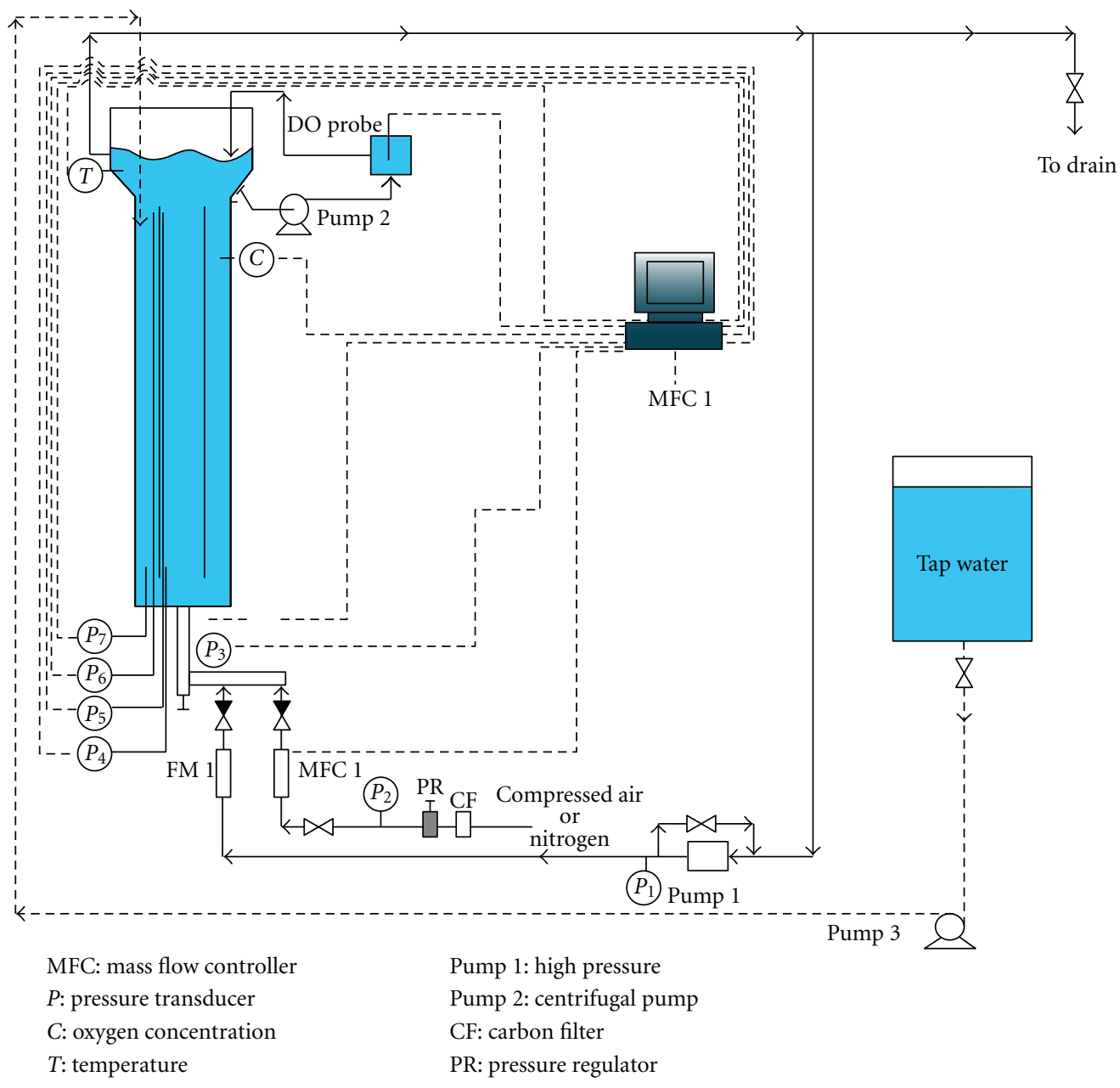

FIGURE 1: Schematic representation of the experimental setup.

the separation section was found to be not very effective in separating microbubbles.

A data acquisition/control system (National Instruments data acquisition board with 16 analog input channels and 2 analog output channels with a sampling rate of $100 \mathrm{k}$ samples/s) was used to monitor the experimental parameters (pressure, temperature, oxygen concentration, conductivity) and to control the superficial gas velocity. Pressure sampling ports were located at the inlet and outlet of the riser and downcomer regions and connected to fast response pressure transducers.

The average pressure values measured at these locations were used to determine gas holdup in the riser using the following expression:

$$
\varnothing_{\text {Riser }}=1-\frac{\left(P_{4}-P_{5}\right)}{\rho_{L} g H_{\text {Riser }}},
$$

where $\varnothing_{\text {Riser }}$ gas holdup in the riser, $\overline{P_{4}}$ mean pressure at the riser entrance $(\mathrm{Pa}), \overline{P_{5}}$ mean pressure at riser outlet $(\mathrm{Pa})$, $\rho_{L}$ liquid density $\left(\mathrm{kg} / \mathrm{m}^{3}\right), g$ acceleration of gravity $\left(\mathrm{m} \mathrm{s}^{-2}\right)$, $H_{\text {Riser }}$ height of the draft tube $(\mathrm{m})$.
A similar approach was used for determining the average gas holdup in the downcomer.

The "Power Spectral Density Function" of the pressure signals was analyzed off-line and used to identify the flow regimes in a fashion similar to that used by Vial et al. [31] and by Gourich et al. [32].

The liquid circulation velocity in the ALR was determined using the conductivity tracer technique in which $25 \mathrm{~mL}$ of a $3 \mathrm{M} \mathrm{NaCl}$ solution was injected from the top of the column $20-30 \mathrm{~mm}$ above the conductivity meter placed in the reactor. The conductivity of the solution passing the probe was continuously monitored and sampled at the rate of 100 samples per second to ensure significance of high-frequency signals (typical results are shown in Figure 2). The resulting data file was then analyzed offline using Labview's harmonic analysis capabilities, thereby achieving high reproducibility in estimating the cycle time and circulation velocity. The analysis ignored the first peak, which was found to be strongly affected by slight variations in tracer injection, and incorporated 3 to 8 cycles depending on the mixing intensity. 


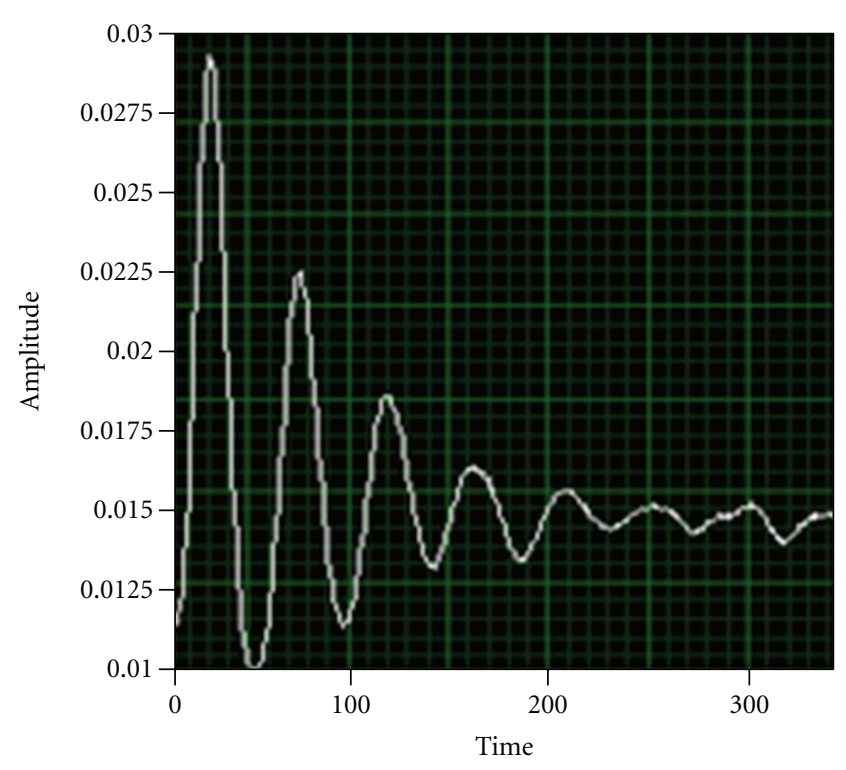

Figure 2: Temporal variation of conductivity (time in seconds).

Since the distance travelled by the tracer is more than twice the length of the riser, the following equation is used to obtain conservative estimates of the liquid circulation velocity:

$$
U_{\text {Circ }}=\frac{2 * H_{\text {Riser }}}{t_{\text {Circ }}},
$$

where $t_{\text {Circ }}$ average circulation time $(s), U_{\text {Circ }}$ average liquid circulation velocity $\left(\mathrm{m} \mathrm{s}^{-1}\right)$.

The $25 \mathrm{~mm}$ diameter transonic sparger used in this investigation (Figure 3 ) is a scaled up version of the sparger previously used to produce fine gas/liquid dispersions, with bubble sizes as small as $35 \mu \mathrm{m}$ and interfacial area as high as $3,500 \mathrm{~m}^{2} / \mathrm{m}^{3}$, being achieved in the presence of SDS [33]. It focuses energy dissipation rate within the throat of an annular venturi where a very high-speed two-phase jet is formed. The divergent section of the sparger helps in recovering the substantial kinetic energy of the two-phase jet and minimizes excessive mixing at the point where the sparged gas/liquid mixture is introduced.

At relatively low velocities, the gas phase is dispersed into small bubbles as a result of the very high local energy dissipation rates prevalent in the venturi throat. The fine bubbles thus formed tend to coalesce as they migrate into the lower energy dissipation regions prevalent in the sparger's divergent section as well as in the ALR riser section. However, the rate at which these bubbles coalesce is strongly affected by the interfacial characteristics of the gas/liquid system used (a factor that is strongly affected by the presence of contaminants). On the other hand, when the operating conditions are such that the velocity of the two-phase flow within the throat is larger than its sonic velocity, a standing shock wave is formed in the divergent section in a fashion similar to that present in the DeLaval nozzle [34]. Very fine bubbles are thus generated as the gas liquid dispersion passes through the high energy dissipation region in the

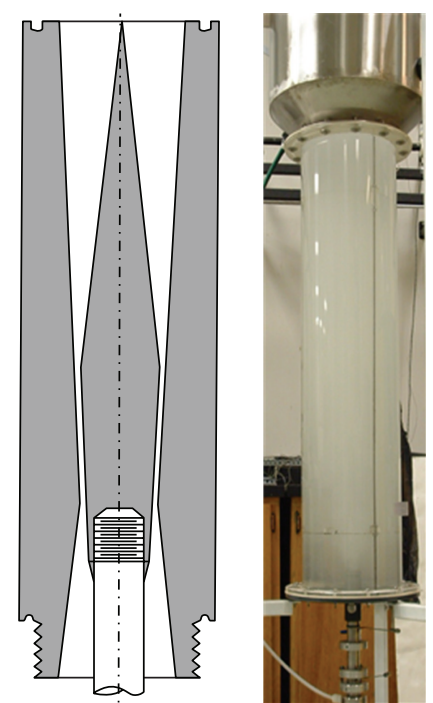

FIGURE 3: Schematic representation of the two-phase transonic sparger and its use to generate fine bubble dispersions $\left(U_{G}=\right.$ $\left.0.01 \mathrm{~m} \mathrm{~s}^{-1}\right)$.

standing wave. The use of a modified version of this sparger reportedly doubled the capacity of the bioreactors operated by "Royal DSM" at their plant in The Netherlands [35], whereas an earlier fixed-throat version yielded gas holdups as high as $\mathcal{E}_{G}=0.45$ at a superficial velocity of $0.03 \mathrm{~m} \mathrm{~s}^{-1}$ [36]. Using this sparger and a slightly modified geometry of the present setup, inter phase mass transfer coefficients as high as $0.13 \mathrm{~s}^{-1}$ were achieved at low superficial velocities in a slowly coalescent salt-containing system [37].

The aforementioned bubble breakage/coalescence mechanisms resulted in the gas dispersion performance of the transonic sparger being influenced by [33]

(i) pressure drop across the sparger,

(ii) gas to liquid mass flow ratio in the sparger,

(iii) coalescence tendencies of the system.

For the case of aqueous SDS solutions, the size of bubbles formed by dual-phase transonic sparger (which varied between 35 and $1,700 \mu \mathrm{m}$ ) was thus estimated using the following correlation developed by Al Taweel et al. [33]:

$$
d_{32}=1.57 \times 10^{3} C_{s}^{-0.4} \Delta P_{\text {Sparger }}{ }^{-0.35} Q_{L}{ }^{-0.26}\left(\frac{Q_{G}}{Q_{L}}\right)^{0.70},
$$

where $d_{32}$ sauter mean bubble diameter, $(\mu \mathrm{m}), C_{S}$ surfactant concentration, SDS (ppm), $\Delta P_{\text {Sparger }}$ pressure drop across the sparger $(\mathrm{Pa}), Q_{G}$ gas volumetric flow rate $\left(\mathrm{m}^{3} \mathrm{~s}^{-1}\right), Q_{L}$ liquid volumetric flow rate $\left(\mathrm{m}^{3} \mathrm{~s}^{-1}\right)$.

One of the advantages of using this sparger is the ability to adjust the bubbler size of the gas liquid dispersion introduced into the ALR without interrupting the operation. This can be achieved by adjusting the gas to liquid ratio and/or the pressure drop across the sparger (the latter can be achieved by turning the spindle which moves the conical sparger core upwards and/or downwards, resulting in altering the cross-sectional area of the throat). 
In the present investigation, the liquid mass flow rate was kept constant throughout the experiments $\left(W_{L}=\right.$ $0.06 \mathrm{~kg} / \mathrm{s}$ ), whereas the gas mass flow rate was varied between $1.3 * 10^{-4}$ and $1 * 10^{-3} \mathrm{~kg} / \mathrm{s}$. The pressure drop across the sparger was maintained at the desired value by adjusting the cross-sectional area of annual channel in the throat. Most of the experiments were performed at two pressure drops across the sparger $(140 \mathrm{kPa}, 280 \mathrm{kPa})$ but several systematic investigations of the effect of bubble size were conducted using five different pressure drops across the sparger (70, 140, $210,280,350 \mathrm{kPa}$ ) at a constant liquid to gas mass flow ratio of 150 .

The effect of the operating conditions on the size of the bubbles generated by the twin fluid transonic sparger in the present investigation (predicted using (3)) is shown in Figure 4 . The size of the smaller bubbles predicted to have been achieved in the present investigation compares well with those obtained by Al-Mashhadani et al. $\left(d_{32}=550 \mu \mathrm{m}\right)$ and those obtained by Kawashima et al. using a $50 \mathrm{ppm} 3-$ pentanol solution $(189-358 \mu \mathrm{m})$.

The operational characteristics of the unit were investigated using the system air/tap water to which minute quantities (0 to $50 \mathrm{ppm}$ ) of sodium dodecyl sulfonate (SDS) surfactant were introduced in order to simulate the slow coalescence behavior encountered in most industrial streams. This system was selected because it is nonvolatile and nontoxic and does not degrade quickly. Its static/equilibrium interfacial characteristics are well known, and it is commonly used to test the effect of interfacial properties on the performance of gas/liquid contactors [7, 21, 33, 38, 39].

A total of 82 runs were conducted in order to determine the effect of various operating conditions on the hydrodynamic performance of the ALR. The range of experimental conditions investigated is given in Table 2 .

\section{Results and Discussion}

3.1. Flow Regime. The power spectrum density function (PSDF) of the pressure signal in both the riser and downcomer regions was found to provide a good indication of the flow conditions in their respective regions. However, since the maximum superficial gas velocity used in this investigation is much lower than that at which transition has been reported (typically $\geq 0.05 \mathrm{~m} \mathrm{~s}^{-1}$ particularly in coalescence-retarding systems), the exploratory results reported here apply only to the homogeneous flow regime. This is confirmed by the absence of any sudden changes in the variation of gas holdup with $U_{G}$ (e.g., Figure 6).

The frequency, intensity, and breadth of the pressure differential signal spectrum were found to be strongly affected by the flow conditions. For example, very strong pressure fluctuations were observed to occur when the transonic sparger was operated as a single-phase distributor even in the presence of surfactants (Figure 5(a)), while the signal spectrum was also found to be very broad. Conversely, the pressure fluctuations obtained when the dual-phase transonic sparger was operated at a pressure drop of $350 \mathrm{kPa}$ were found to be weak and bounded within a very narrow

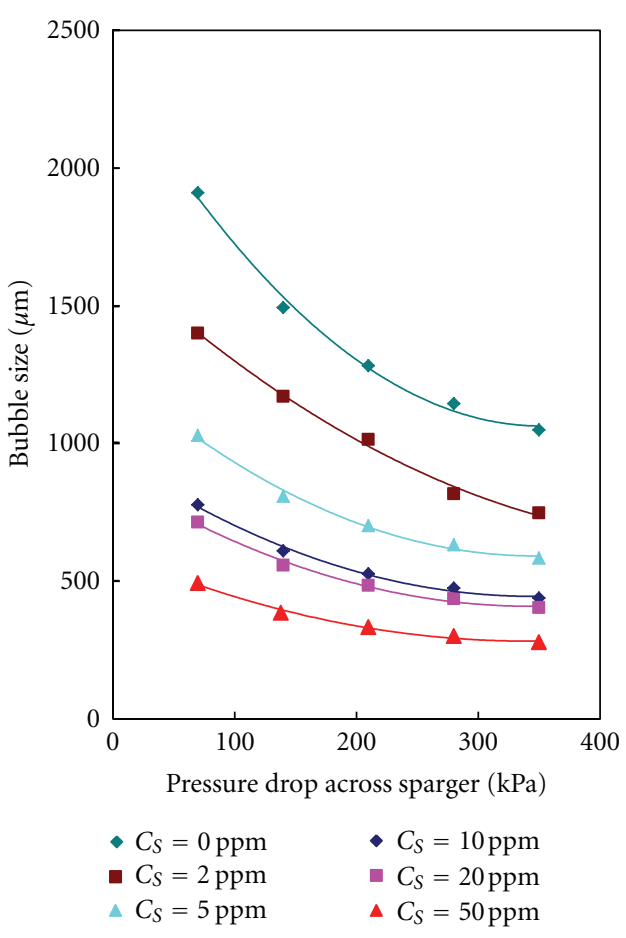

FIGURE 4: Effect of sparger pressure drop on the predicted size of bubbles generated by the dual-fluid transonic sparger $\left(U_{G}=\right.$ $\left.0.008 \mathrm{~m} \mathrm{~s}^{-1}, W_{L} / W_{G}=150\right)$.

frequency range (Figure 5(b)). This dramatic difference can be attributed to inefficient dispersive action of the sparger when it is operated using air only (and the consequent formation of a wide range of bubble sizes, mostly coarse ones), whereas a narrowly sized fine bubble dispersion was observed to occur when the sparger is operated using an air-water dispersion (particularly at high pressure drops and elevated surfactant concentrations).

As can be seen from Figure 6, both the characteristic frequency and the intensity of the pressure fluctuations were found to vary with the operating conditions. The intensity of the pressure fluctuations appear to be a function of the bubble size with the intensity increasing as the size of bubbles formed by the sparger becomes larger due to the higher gas flow rates processed (3). Similarly, the fact that the intensity of the pressure fluctuations in the downcomer is higher than the corresponding values in the riser (Figure 6(a)) can be attributed to the need for the bubbles suspended in the downcomer to become larger than those in the riser before they can move against the downwards moving liquid in the downcomer. However, no attempts were made to analyze these results in depth because of the absence of detailed information concerning the size distribution of bubbles formed. It is however interesting to note that the characteristic frequencies obtained by Vial et al. [31] at higher superficial gas velocities $\left(0.07\right.$ to $\left.0.12 \mathrm{~m} \mathrm{~s}^{-1}\right)$ are lower than those obtained in the present investigation (0.3 to $5 \mathrm{~Hz})$ whereas the intensity of their pressure fluctuations $(0.0009$ to $0.6 \mathrm{kPa})$ is within the range observed in the 
TABLE 2: Range of experimental conditions investigated.

\begin{tabular}{lcc}
\hline Superficial gas velocity & $0.0025-0.020$ & $\mathrm{~ms}^{-1}$ \\
SDS concentration & $0-50$ & $\mathrm{ppm}$ \\
Equilibrium surface tension & $72.0-44.1$ & $\mathrm{mN} / \mathrm{m}$ \\
Temperature & $25 \pm 2$ & - \\
Gas holdup in the riser $( \pm 4 \%)$ & $0.007-0.14$ & ${ }^{\circ} \mathrm{C} \mathrm{s}^{-1}$ \\
Gas holdup in the downcomer $( \pm 4 \%)$ & $0-0.11$ & $\mathrm{~s}$ \\
Liquid circulation velocity $( \pm 4 \%)$ & $0.57-1.3$ & $18-40$ \\
Mixing time $( \pm 7 \%)$ & $70-350$ & $\mathrm{kPa}$ \\
Pressure drop across sparger & 0.06 & $\mathrm{~kg} / \mathrm{s}$ \\
Mass Flow rate of water through the sparger & $0.0021-0.017$ & - \\
Gas to liquid mass flow ratio in the sparger & \\
\hline
\end{tabular}

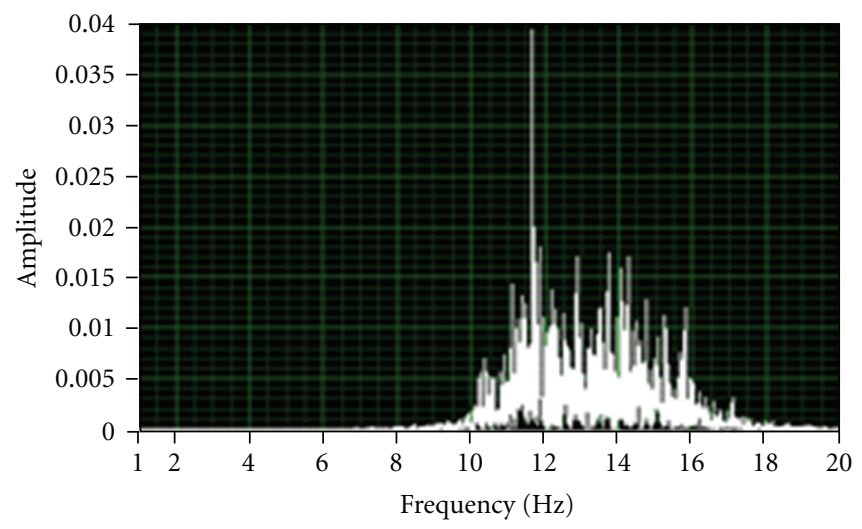

(a) Single phase sparger

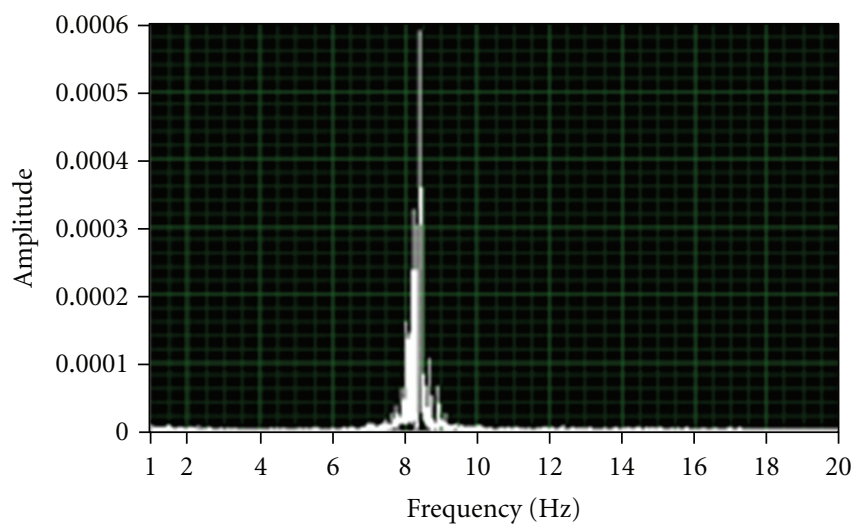

(b) Dual-Fluid operation $\left(\Delta P_{S}=350 \mathrm{kPa}\right)$

FIgURE 5: Effect of sparger operational mode on the PSDF of the pressure in the riser $\left(U_{G}=0.005 \mathrm{~m} \mathrm{~s}^{-1}, C_{S}=50 \mathrm{ppm}\right)$.

present investigation. This variation could be attributed to the different geometrical designs and sparger types used in the two investigations, as well as differences in the systems investigated.

Due to the increasing tendency to form finer bubbles, the presence of surfactants was found to reduce the pressure fluctuation intensity and frequency in both the riser and downcomer regions with this trend increasing as the surfactant concentration increased.

3.2. Gas Holdup. Hydrodynamics and mass transfer rates are the most important parameters used in assessing the performance of air lift reactors. These parameters are sensitive to the reactor design configuration as well as operational variations such as superficial gas velocity, the size of bubbles introduced at the base of the riser, and the bulk/interfacial properties of the system. However, ALRs suffer from the limited number of parameters that can be used to control their performance. Thus, whereas the superficial gas velocity can be easily modified in conventional ALRs, it is not possible to change the bubble size without stopping the operation in order to change the sparger. The use of transonic spargers thus provides the opportunity to change the bubble size without disrupting the operation.
In rapidly coalescent media, the bubble size introduced at the base of the ALR changes rapidly as the bubbles ascend in the riser in an attempt to approach quasisteady conditions $[11,15,16]$. Consequently, the size of bubbles formed at the sparger has little influence on that prevailing in the riser in rapidly coalescent media, whereas the size of bubbles prevailing throughout the riser remains close to that formed at the sparger in the case of slowly coalescent media. The relative importance of sparger design was thus found to depend strongly on the interfacial properties of the liquid phase [14, 16, 39-42].

Similar observations were obtained in the present investigation where, for rapidly coalescent system, the gas holdup in the riser was found to increase with increasing gas velocity in a nearly linear fashion without significantly increasing gas holdup in the downcomer (Figure 7). This observation is very similar to that reported when perforated plate spargers are used and can be attributed to the prevalence of relatively large bubbles which tend to disengage easily in the separator section. The gas holdup in the riser and downcomer sections increased only slightly when the pressure drop across the sparger was increased in order to introduce finer bubbles at the bottom of the riser. This limited sensitivity to the size of bubbles can be attributed to the relatively fast rate at which the dynamic equilibrium between the breakage 


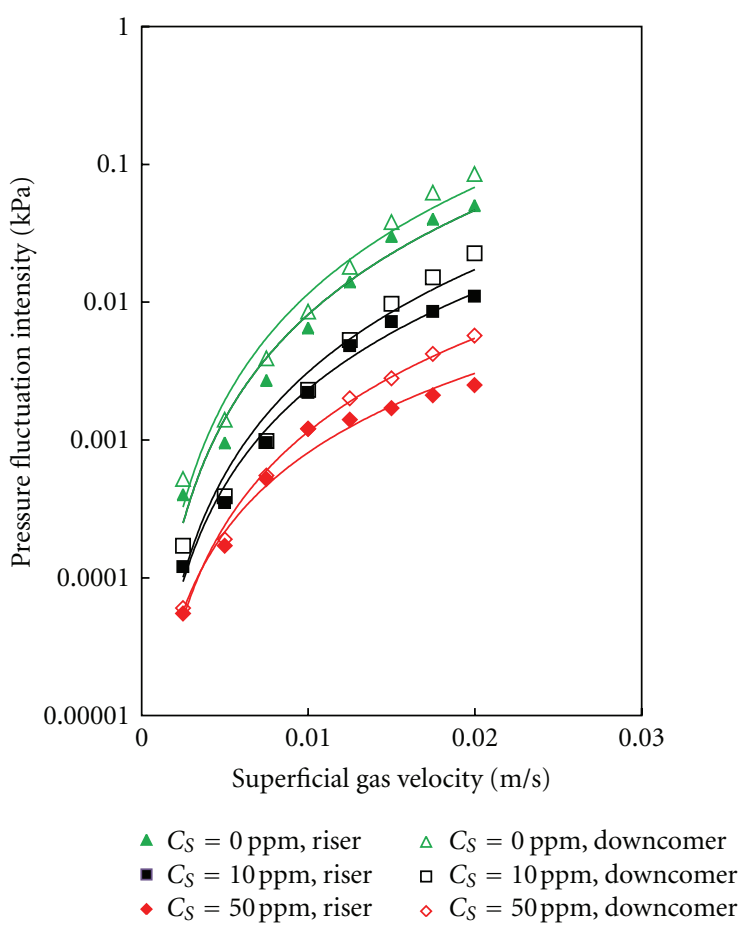

(a) Fluctuation intensity

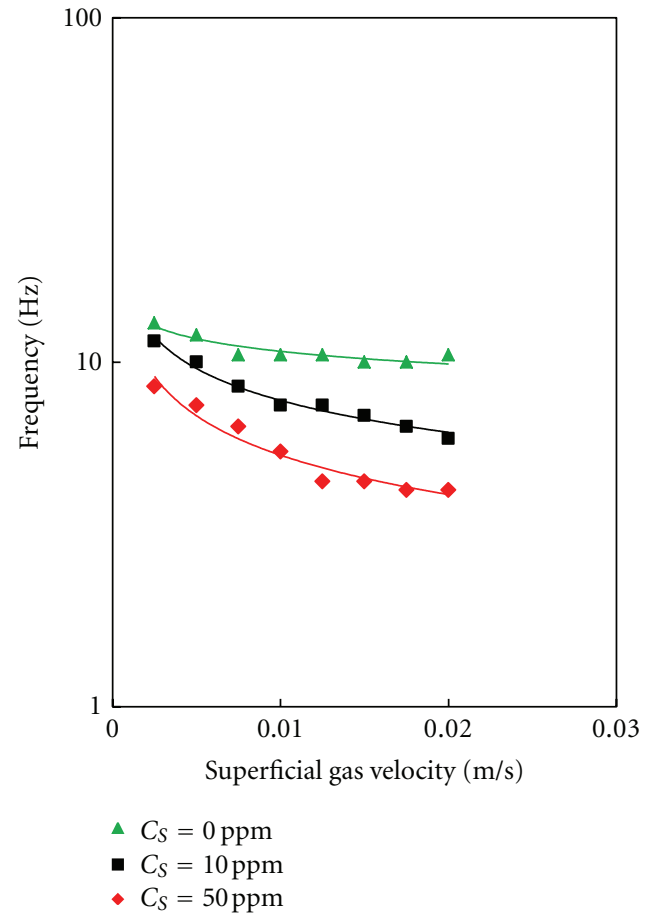

(b) Characteristic frequency (riser)

FIGURE 6: Effect of superficial gas velocity and surfactant concentration on the intensity and characteristic frequency of pressure fluctuations $\left(\Delta P_{S}=280 \mathrm{kPa}\right)$.

and coalescence processes is approached in tap water. Consequently, the difference in gas holdup between the riser and downcomer was found to increase significantly with increasing superficial gas velocity.

Although transonic spargers are not ideally suited for the case of rapidly coalescent systems, the results depicted in Figure 8 clearly show that, in the case of the air/water system, they are capable of generating gas holdups that are comparable to the values obtained using plates with $0.6 \mathrm{~mm}$ perforations [40] but higher than those induced by perforated plate spargers equipped with $1 \mathrm{~mm}$ perforations or larger.

The impact of coalescence retardation on the gas holdup performance of ALR was found to be very pronounced when transonic spargers are used for aeration purposes. The visual appearance of the dispersion thus acquired a "milky" appearance due to the formation of extrafine bubble with the optical density of the gas/liquid dispersion increasing with increasing gas flow rate and/or pressure drop across the sparger. The noise made by the disengaging bubbles also changed from that of a vigorous splashing sound (in the case of tap water) to the more uniform hiss reported by Nicol and Davidson [38] for the case of surfactant-contaminated water. However, some of the fine bubbles present in the riser were entrained in liquid circulating in the downcomer thereby contributing towards increasing gas holdup in that region.

The effect of coalescence retardation on the gas holdup in the riser is depicted in Figure 9 which clearly shows that, for any particular surfactant concentration, gas holdup in the riser increases significantly as smaller bubbles are introduced into the ALR with the effect being most pronounced at higher surfactant concentration. The gas holdup achieved in the slowly coalescent aqueous solutions containing 50 ppm SDS is consequently 4-fold larger than that obtained in the rapidly coalescent air/water system.

This can be mainly attributed to the ability of the transonic sparger to form smaller bubbles in the case of slowly coalescent systems, with the fine bubbles formed at the sparger tip tending to maintain their size for a longer period as they ascend through the surfactant-containing liquid present in the riser. This is clearly evident from the results depicted in Figure 9 where the gas holdup in the riser was found to be very sensitive to the size of bubbles introduced at the bottom of the riser with the coalescence tendencies of the liquid present in the riser playing a secondary role.

Furthermore, for the case at hand (i.e., SDS surfactant and transonic sparger), there is no indication of the existence of a critical concentration beyond which no changes in gas holdup take place. This can be mainly attributed to the ability of the transonic sparger to form smaller bubbles in the case of slowly coalescent systems, with the fine bubbles formed by the sparger tending to maintain their size for a longer period as they ascend through the surfactantcontaining liquid present in the riser. This is clearly evident from the results depicted in Figure 10 where the gas holdup in the riser was found to be very sensitive to the size of bubbles (predicted using (3)) introduced at the bottom of the riser, with the coalescence tendencies of the liquid 


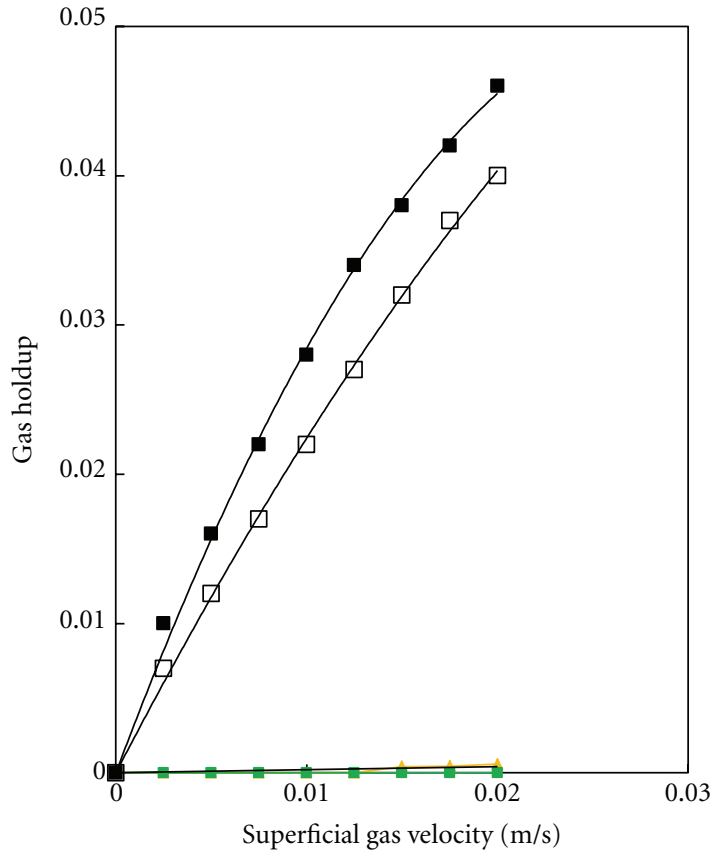

- $\operatorname{Riser}\left(\Delta P_{S}=280 \mathrm{kPa}\right) \quad \square \quad \operatorname{Riser}\left(\Delta P_{S}=140 \mathrm{kPa}\right)$

Downcomer $\left(\Delta P_{S}=280 \mathrm{kPa}\right) \rightarrow$ Downcomer $\left(\Delta P_{S}=140 \mathrm{kPa}\right)$

FIGURE 7: Effect of superficial gas velocity on the riser gas holdup for a rapidly coalescent system $\left(C_{S}=0 \mathrm{ppm}\right)$.

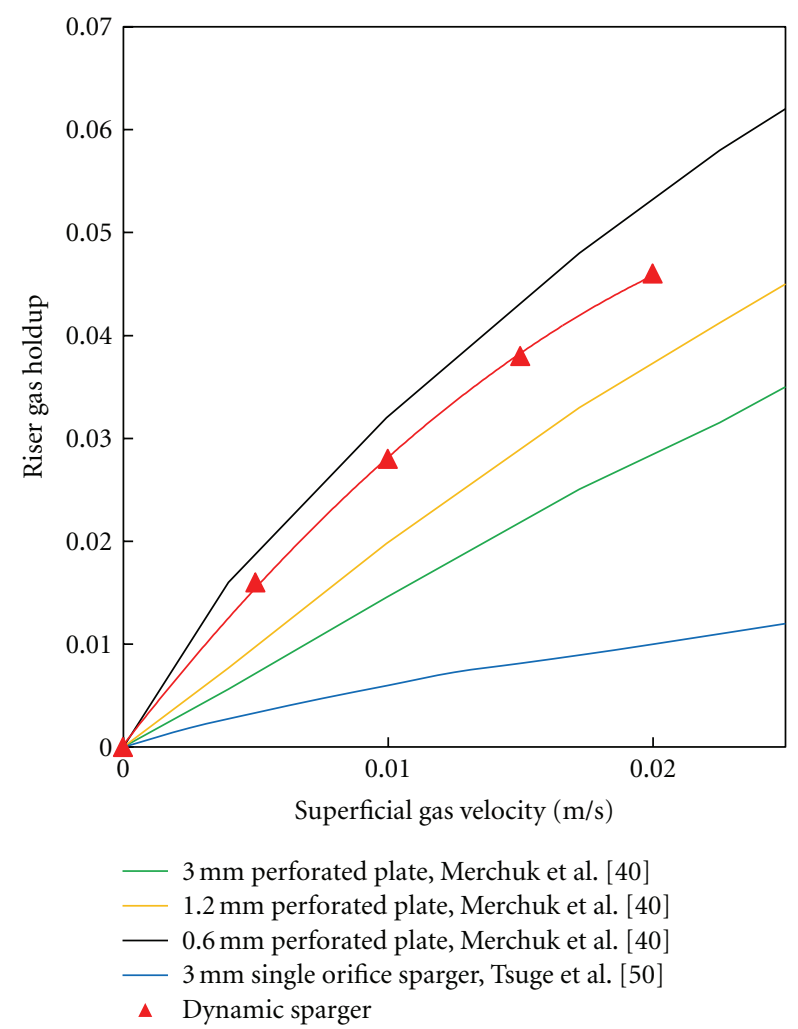

FIGURE 8: Effect of sparger design on gas holdup in the riser $\left(\Delta P_{S}=\right.$ $280 \mathrm{kPa}$ ).

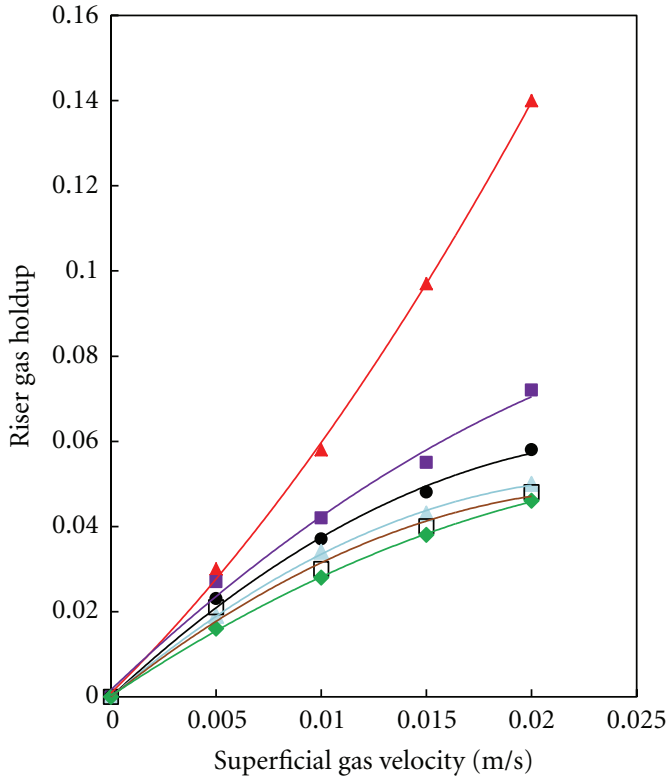

$\Delta C_{S}=50 \mathrm{ppm}$

$\triangle C_{S}=5 \mathrm{ppm}$

- $C_{S}=20 \mathrm{ppm}$

$\square C_{S}=2 \mathrm{ppm}$

- $C_{S}=10 \mathrm{ppm}$

- $C_{S}=0$ ppm

FIGURE 9: Effect of coalescence retardation gas holdup in the riser (transonic sparger, $\Delta P_{S}=280 \mathrm{kPa}$ ).

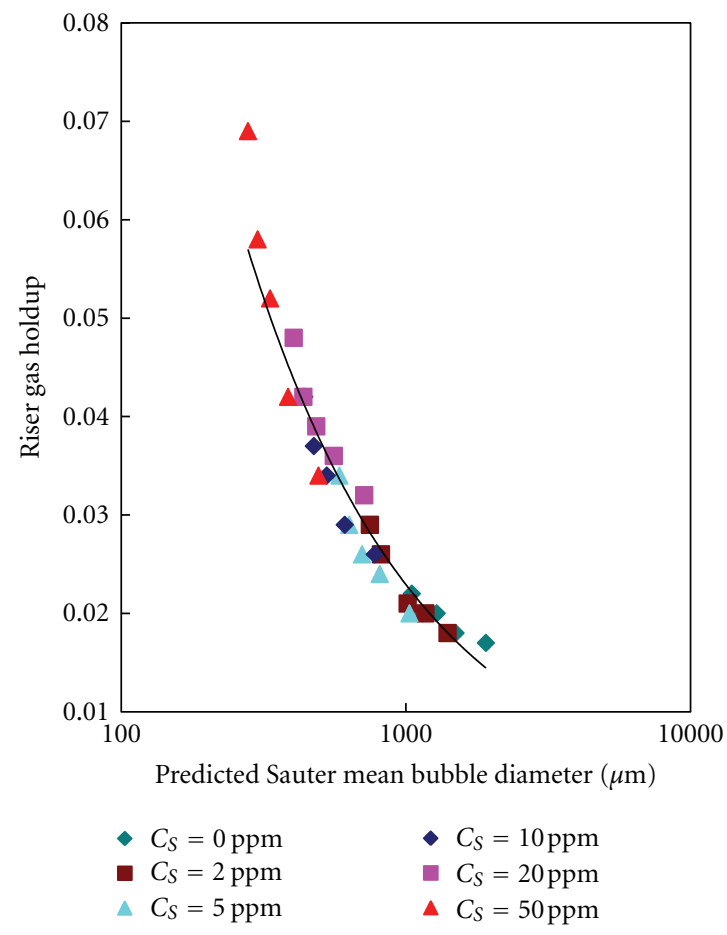

FIGURE 10: Effect of bubble size on the riser gas holdup $\left(U_{G}=\right.$ $\left.0.008 \mathrm{~m} \mathrm{~s}^{-1}, W_{L} / W_{G}=150\right)$. 
present in the riser playing a secondary role. Unfortunately, the fine bubbles generated by the transonic sparger have reduced gas/liquid slip velocities and can thus be more easily reentrained into the downcomer stream thereby reducing the difference in gas holdup between the riser and downcomer sections.

The effect of surfactant concentration on the difference in riser and downcomer gas holdups (Figure 11) suggests that the gas holdup difference is highest for the rapidly coalescent air/water system and decreases quickly in the presence of surfactants. Although such a conclusion is expected to be generally true, the extent to which it occurs is strongly influenced by the hydrodynamic conditions prevalent in the gas disengagement section. Greater attention should therefore be paid to the design of the gas disengagement section whenever fine bubbles are used to promote gas/liquid contacting in order to ensure high levels of gas/liquid separation and the inducement of elevated liquid circulation velocities.

However, even with the inefficient separator used in the present investigation, the riser gas holdups obtained at the low superficial velocities tested are quite high in comparison to those typically reported in the literature. Furthermore, they could have been higher if

(i) longer risers were used (which would provide greater opportunity for the fine bubbles to coalesce into larger ones that can be more easily separated), or

(ii) a more effective separator design (which can eliminate most of the bubble reentrainment in the downcomer) was used.

A comparative evaluation of the transonic sparger with other sparger designs is complicated by the need to utilize liquids with identical coalescence retarding characteristics. This task is however hindered by the paucity of investigations in which ALR performance is systematically investigated using liquids of different interfacial characteristics (hence different coalescence retardation rates). Figure 11 compares the riser gas holdups obtained in the present investigation with those obtained in the presence of various contaminants such as salts [39], alcohols [21, 43], and a series of other compounds [44]. It clearly shows the advantage of using the transonic sparger which is capable of generating fine bubbles in slowly coalescing systems whereby the holdups obtained in this investigation are about 5 -fold higher than those obtained in the presence of $50 \mathrm{ppm}$ of alcohol (using $1 \mathrm{~mm}$ perforated plate sparger) and are slightly higher than those obtained in the presence of $250 \mathrm{ppm}$ of isoamyl alcohol or $1,000 \mathrm{ppm}$ of benzoic acid. The holdups recently reported by Moraveji et al. [7] using $5 \mathrm{ppm}$ SDS solution are similar to those reported by Muthukumar and Velan [44] and are therefore not depicted in Figure 11. On the other hand, using a single orifice nozzle $(3.5 \mathrm{~mm})$ by El-Azher et al. [20] resulted in gas holdups below $\varepsilon_{G}=0.03$ for the superficial velocities tested in this work $\left(U_{G} \leq 0.02 \mathrm{~m} \mathrm{~s}^{-1}\right)$.

3.3. Circulation Velocity. The liquid circulation velocity is the main hydrodynamic parameter which differentiates

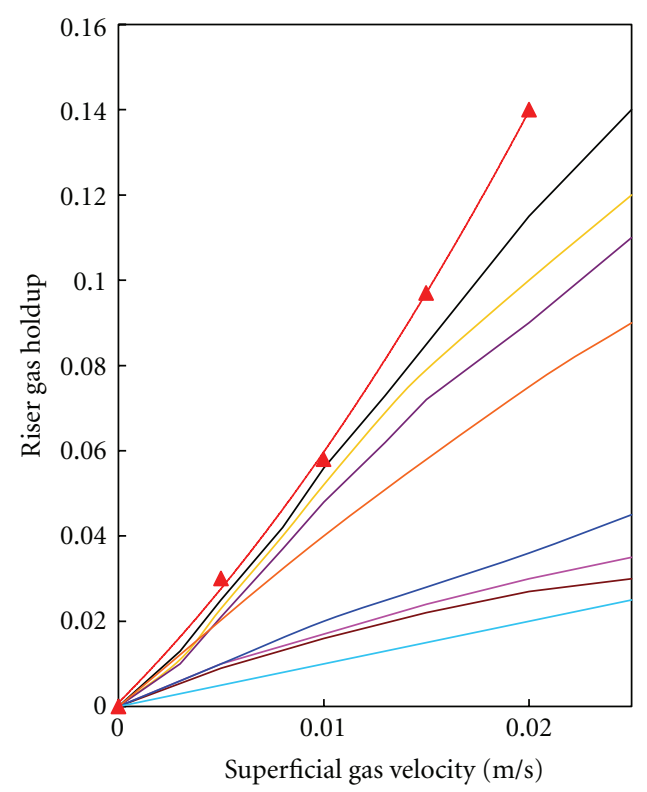

- $1 \mathrm{~mm}$ perforated plate, Al Masry and Dukkan [21], 50 ppm octanol

— $1 \mathrm{~mm}$ perforated plate, Al Masry and Dukkan [21], 50 ppm polypropylene glycol

$1 \mathrm{~mm}$ perforated plate, Muthukumar and Velan [44], $1000 \mathrm{ppm}$ benzoic acid

— $1 \mathrm{~mm}$ perforated plate, Muthukumar and Velan [44], 250 ppm isoamyl alcohol

— $1 \mathrm{~mm}$ perforated plate, Muthukumar and Velan [44], $2500 \mathrm{ppm}$ propanol

— $1 \mathrm{~mm}$ perforated plate, Wachi et al. [43], $1000 \mathrm{ppm}$ ethanol

- $1 \mathrm{~mm}$ perforated plate, Wachi et al. [43], $5000 \mathrm{ppm}$ glycerol

$0.5 \mathrm{~mm}$ perforated plate, Snape et al. [39], $800 \mathrm{ppm} \mathrm{MgSO}_{4}$

- $0.5 \mathrm{~mm}$ perforated plate, Snape et al. [43], $800 \mathrm{ppm} \mathrm{CaCl}_{2}$

— $0.5 \mathrm{~mm}$ perforated plate, Snape et al. [39], $800 \mathrm{ppm} \mathrm{NaCl}$

- Dynamic sparger, SDS $50 \mathrm{ppm}$

FIGURE 11: Effect of sparger type and contaminants on gas holdup in the riser.

ALR from bubble columns and significantly affects the gas holdups achievable in the riser and downcomer regions, the axial and radial mixing intensities, the mixing time, the overall mass transfer coefficients, as well as the ability to suspend catalyst particles. It is driven by difference in gas holdup between the riser and the downcomer zones [45], and its magnitude is determined by the balance between the driving force and the overall hydrodynamic resistance in the various parts of the reactor.

As shown in Figure 12, the liquid circulation velocity for the rapidly coalescent air/water system was found to increase with increasing superficial gas velocity, reaching a velocity of $1.3 \mathrm{~m} \mathrm{~s}^{-1}$ at $U_{G}=0.02 \mathrm{~m} \mathrm{~s}^{-1}$ when high pressure drops are applied across the sparger to generate fine bubbles. The circulation velocity is however reduced when the somewhat coarser bubbles are generated at the lower pressure drop of $140 \mathrm{kPa}$. However, it is important to note that, in all experiments conducted using the rapidly coalescent air/water system, virtually complete disengagement of bubbles took 


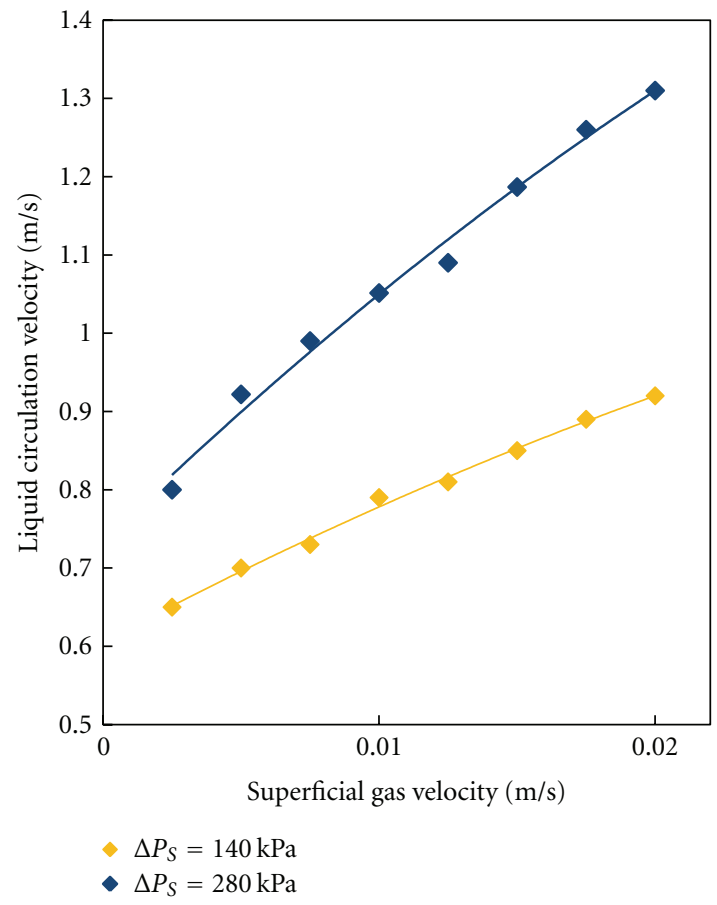

Figure 12: Effect of superficial Gas velocity on liquid circulation rates in rapidly coalescent systems $\left(C_{S}=0 \mathrm{ppm}, W_{L}=0.06 \mathrm{~kg} / \mathrm{s}\right)$.

place in the separator design adopted in the present investigation and few bubbles were observed to be entrained into the downward recirculating stream (Figure 5).

The presence of trace quantities of surfactants in the process stream was found to result in the formation of smaller bubbles by the transonic sparger. These bubbles are usually much smaller than those prevalent under the dynamic equilibrium that could prevail in the riser and will therefore tend to undergo net coalesce as they ascend in it. The rate at which coalescence takes place will be dictated by the nature and concentration of the contaminant (which determines the coalescence retardation effect) as well as by the hydrodynamic conditions in the riser. Taken alone, this phenomenon is expected to result in increasing the gas holdup in the riser section at increasing surfactant concentrations with the consequent increase in circulation rate. However, counteracting that effect is the tendency of small bubbles present at the top of the riser to be entrained into the downcomer flow, resulting in significantly increasing the gas holdup in that region. The balance between those two opposing trends is mainly controlled by the design of the gas disengagement unit and its ability to separate small bubbles from the recirculating stream. This task is usually rendered more difficult the smaller the bubbles are.

In the presence of surfactants, the effect of superficial gas velocity on the value of the circulation velocity was found to depict the same trends as shown in Figure 12. However, the magnitude of the induced liquid circulation was much lower (Figure 13). This phenomenon can be attributed to the fact that whereas the extrafine bubbles generated at high surfactant concentrations tend to increase

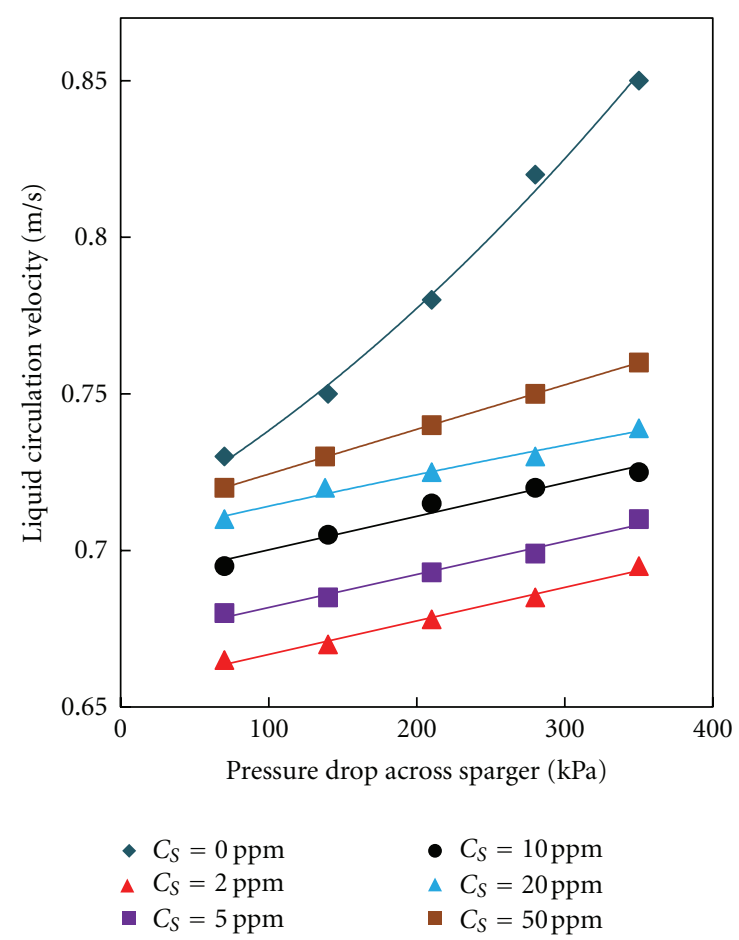

FIGURE 13: Effect of surfactant concentration on liquid circulation velocity $\left(U_{G}=0.008 \mathrm{~m} \mathrm{~s}^{-1}, W_{L} / W_{G}=150\right)$.

the gas holdup in the riser (Figure 9), they also can be more easily entrained in the downcomer stream. Depending on the relative magnitude of the two, the net pressure difference between the riser and downcomer regions can be reduced. This observation is similar to that reported by several investigators $[7,16,21,42]$ who observed a significant reduction in circulation velocity in the presence of amphiphilic contaminants.

Figure 13 clearly shows that an increase in the pressure drop across the transonic sparger had a significant effect on liquid circulation velocities in the case of the rapidly coalescent air/water system but the impact is much less in the case of slowly coalescent systems. This could be attributed to the fact that finer bubbles are generated at higher pressure drops across the sparger (Figure 4) and to the subsequent impact such a parameter has on the differential gas holdups between the riser and downcomer regions. This interpretation is confirmed by the results obtained concerning the effect of bubble size on liquid circulation velocity that are presented in Figure 14.

The impact that bubble size has on the liquid circulating velocity was determined using the results obtained at a single superficial velocity in which the predicted size of the bubbles generated by the sparger was manipulated by changing the surfactant concentration and/or the pressure drop across it. The results depicted in Figure 14 clearly show that the behavior of the air/water system is significantly different from that of surfactant-containing systems.

In the former case, the liquid circulation velocity could be increased by around $10 \%$ by introducing finer bubbles 


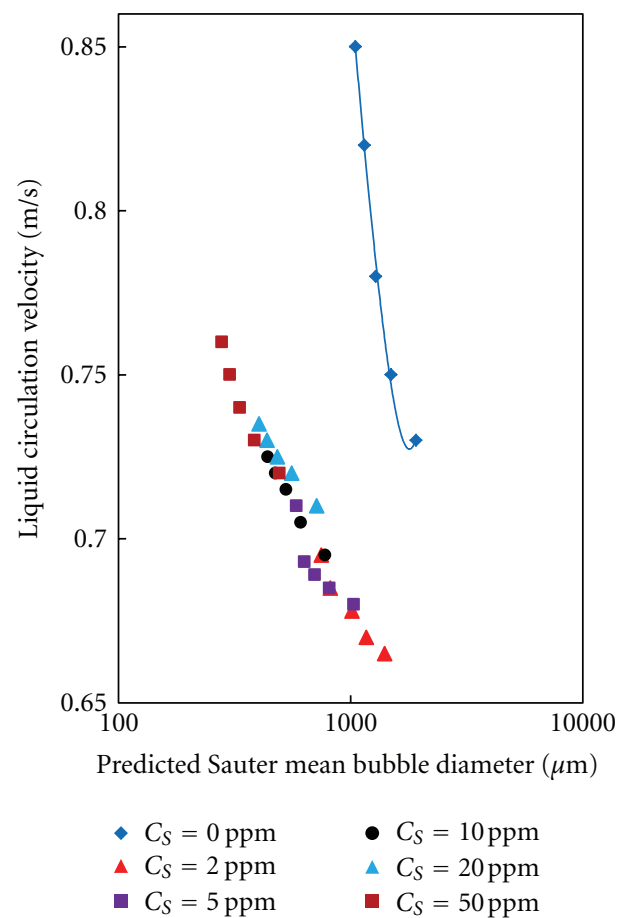

Figure 14: Effect of Bubble size on liquid circulation velocity at different surfactant concentrations $\left(U_{G}=0.008 \mathrm{~m} \mathrm{~s}^{-1}, W_{L} / W_{G}=\right.$ 150).

at the base of the riser. The same trends were observed in the presence of surfactants, but the lower sensitivity to bubble size came as a surprise particularly considering the very strong impact that bubble size has on the gas holdup in the riser (Figure 9). This behavior can be attributed to the inability of the gas disengagement design used in the present investigation to handle the fine bubble sizes encountered in the presence of surfactants. Consequently, a large fraction of the fine bubbles reaching the top of the riser got to be reentrained into the downcomer stream where they either move downwards to the riser entrance or remain suspended until they grow in size to the point where they can rise against the downward moving liquid.

The assumption that the recirculation pattern observed in ALR is induced by the pressure differential between the riser and downcomer regions is confirmed by the data presented in Figure 15 for slowly and rapidly coalescent systems. It clearly shows that the liquid circulation velocity is linearly proportional to the difference in gas holdup between the riser and downcomer regions for both rapidly coalescent and slowly coalescent systems. This is in agreement with the observations made by several investigators such as Chisti and Moo-Young [45], Al-Masry and Dukkan [21], and Muthukumar and Velan [44].

It is interesting, however, to note that, whereas all the results obtained in the presence of surfactants fall on one line, significant difference exists in the efficiency by which the pressure energy utilized in the air/water system is converted into kinetic energy. This is most probably caused by the lower entrainment efficiency exhibited by the less-uniform air/water jets formed at $140 \mathrm{kPa}$ pressure drop (which were observed to spread relatively slowly across the cross-sectional area of the riser and contained some large bubbles that tended to concentrate in the core region where they imparted high velocities to relatively small fraction of the liquid in the riser). On the other hand, the two-phase jets formed at higher pressure drops, or in the presence of surfactants, were found to contain smaller bubbles that are more evenly spread across the cross-section of the riser.

From all the above, it is clear that the dual-fluid transonic spargers can be used to generate fine bubbles when used in conjunction with the slowly coalescent systems encountered in most industrial and environmental systems. It therefore has the potential to overcome the adverse impact resulting from the lower $k_{L}$ values typically associated with the presence of amphiphilic materials in these systems. Unfortunately, the beneficial impact on liquid circulation velocity could not be fully achieved because of the tendency of small bubbles to be entrained into the downcomer stream, thereby lowering the pressure difference between the riser and downcomer regions. In addition, it is important that the entrained small bubbles (which normally are depleted of the gas to be transferred) be removed. Otherwise, these bubbles will act as a sink when they recirculate and mix with the fresh bubbles in the riser.

Significant reduction in the tendency of fine bubbles to be entrained in the recirculating liquid may be achieved by

(i) providing the fine bubbles introduced at the bottom of the riser with a greater opportunity to coalesce into larger bubbles that can be more easily removed in the disengagement section. The use of taller ALR is therefore expected to ameliorate the adverse impact on liquid circulation velocity that is associated with the use of fine bubbles,

(ii) using more efficient disengagement section designs similar to those discussed by Bentifraouine et al. [46], Gavrilescu and Tudose [47], and Merchuk [48].

The importance of properly designing the gas disengagement section was illustrated by Al-Masry et al. [21, 49] who investigated the impact of using open and closed channel configurations on the hydrodynamic and mass transfer performance of a pilot scale ALR. They reported a significant increase in the liquid recirculation velocity when the more efficient open channel configuration was used, particularly in the presence of contaminants that can retard bubble coalescence.

The experimental results obtained in the present investigation clearly show that the liquid circulation velocities achieved using the dual-fluid transonic sparger are much higher than those obtained by using more conventional designs even in the case of the water/air system where the performance of this novel sparger is relatively poor. As shown in Figure 16, the liquid circulation velocities produced using dual fluid transonic sparger are thus about 5-fold larger than those produced by single orifice spargers [20] and about double those produced by $1 \mathrm{~mm}$ perforated plates [49] This is attributed to the ability of novel sparger to produce higher riser gas holdups through the formation of fine gas liquid dispersions. 


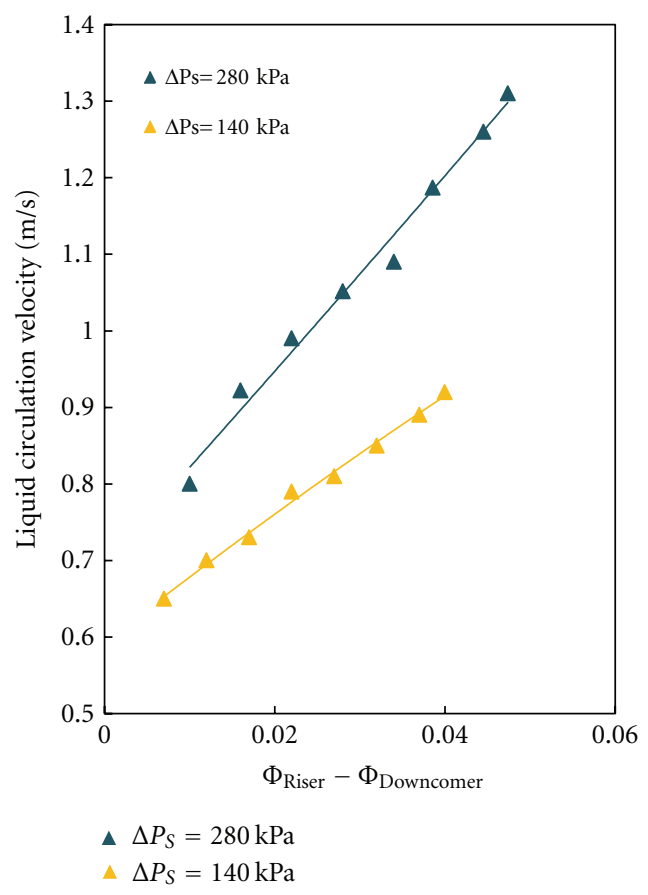

(a) Rapidly coalescent air water system

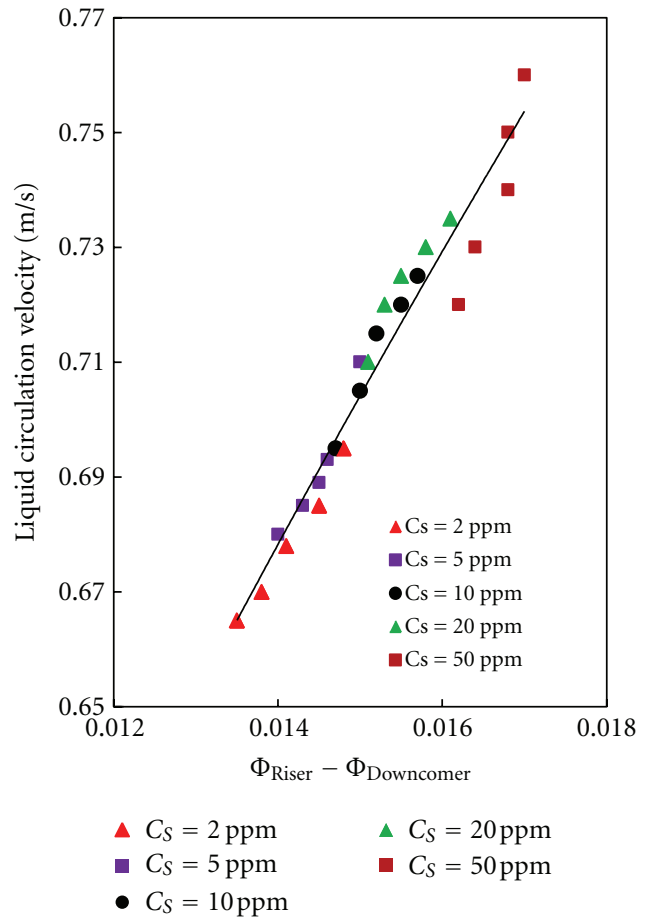

(b) Slowly coalescent surfactant-containing systems

FIGURE 15: The effect of gas holdup differential (between the riser and downcomer regions) on the liquid circulation velocity $\left(W_{L}=0.06 \mathrm{~kg} / \mathrm{s}\right.$, $\left.\Delta P_{S}=280 \mathrm{kPa}\right)$.

The relative advantage of using the dual-fluid transonic sparger on the liquid circulation velocity is even more pronounced in the presence of contaminants. For example, the liquid circulation rates obtained in the present investigation were up to 5-fold larger than those obtained by Muthukumar and Velan [44] in the presence of 2502,500 ppm of contaminants such as isoamyl alcohol, benzoic acid, and propanol (Figure 17). They are however slightly less than double the circulation velocities reported by AlMasry and Dukkan [21] in the presence of up to $100 \mathrm{ppm}$ of ethylene glycol and octanol.

The liquid circulation velocities reported by Moraveji et al. [7] using 5 ppm surfactant solutions (SDS, Tween 80 , Triton X-405) were very low (about $0.12 \mathrm{~m} \mathrm{~s}^{-1}$ at $U_{G}=0.01 \mathrm{~m} \mathrm{~s}^{-1}$ ) mainly because of the inefficient gas disengagement performance of the split-cylinder ALR used in their investigation. Under such conditions, a significant part of the fine bubbles formed in the presence of amphiphilic contaminants will be reentrained in the downcomer flow with the consequent reduction of the liquid circulation velocity. The same issue is probably the reason behind the low circulation velocities reported by El-Azher et al. [20] who used a splitrectangular ALR aerated by a single orifice nozzle $(3.5 \mathrm{~mm})$. They tested the impact of contaminant concentration on the hydrodynamic and mass transfer performance of the unit reaching relatively high concentrations of several alcohols (500-1,000 ppm of 1-propanol, 1-butanol, and methanol).

\section{Conclusions and Recommendations}

The dual-fluid transonic sparger can take advantage of the coalescence retarding properties of most industrial streams and generate very fine bubbles that can engender high gas holdups and large interfacial area of contact between the phases. This is expected to counteract the adverse effect that amphiphilic materials have of the liquid phase mass transfer coefficient, $k_{L}$, thereby enabling for the achievement of large volumetric mass transfer coefficients, $k_{L} a$. Elevated liquid circulation velocities can also be achieved by using this effective sparger, particularly when effective gas/liquid disengagement units are used to separate the fine bubbles emerging from the top of the riser.

The results obtained in the present investigation show that the two-phase transonic spargers can be effectively used to improve the hydrodynamic performance of airlift reactors with up to 5-fold enhancement in riser gas holdup being achievable in the presence of coalescence retarding materials. This resulted in circulation velocities as high as $1.3 \mathrm{~m} \mathrm{~s}^{-1}$ being achieved the low superficial velocity of $0.02 \mathrm{~m} \mathrm{~s}^{-1}$.

The extrafine bubbles generated by the sparger in the presence of surfactants tended to be entrained in the 


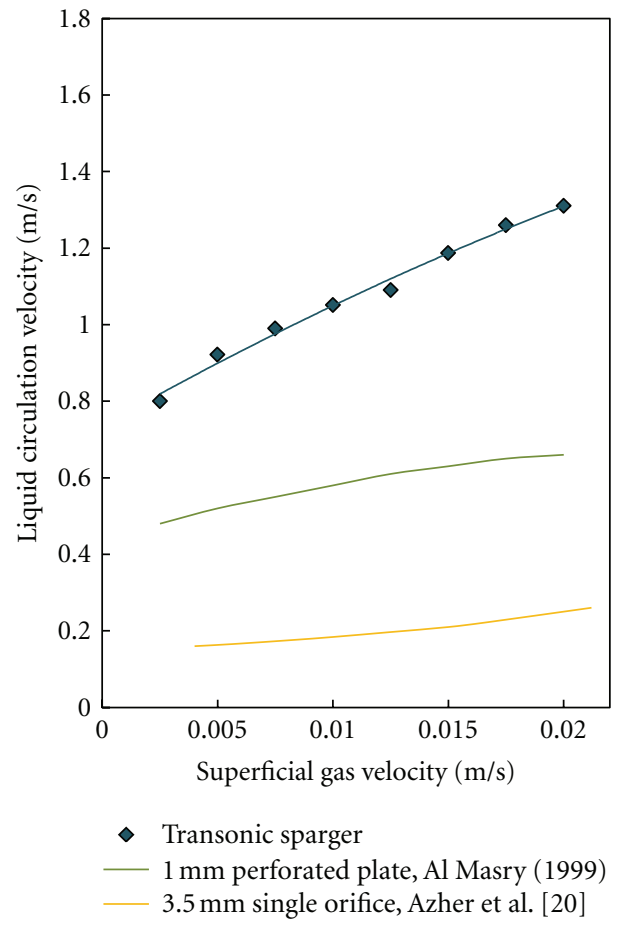

FIGURE 16: Effect of superficial gas velocity and sparger design on the liquid circulation velocity in $\operatorname{ALR}\left(C_{S}=0 \mathrm{ppm}, \Delta P_{S}=280 \mathrm{kPa}\right)$.

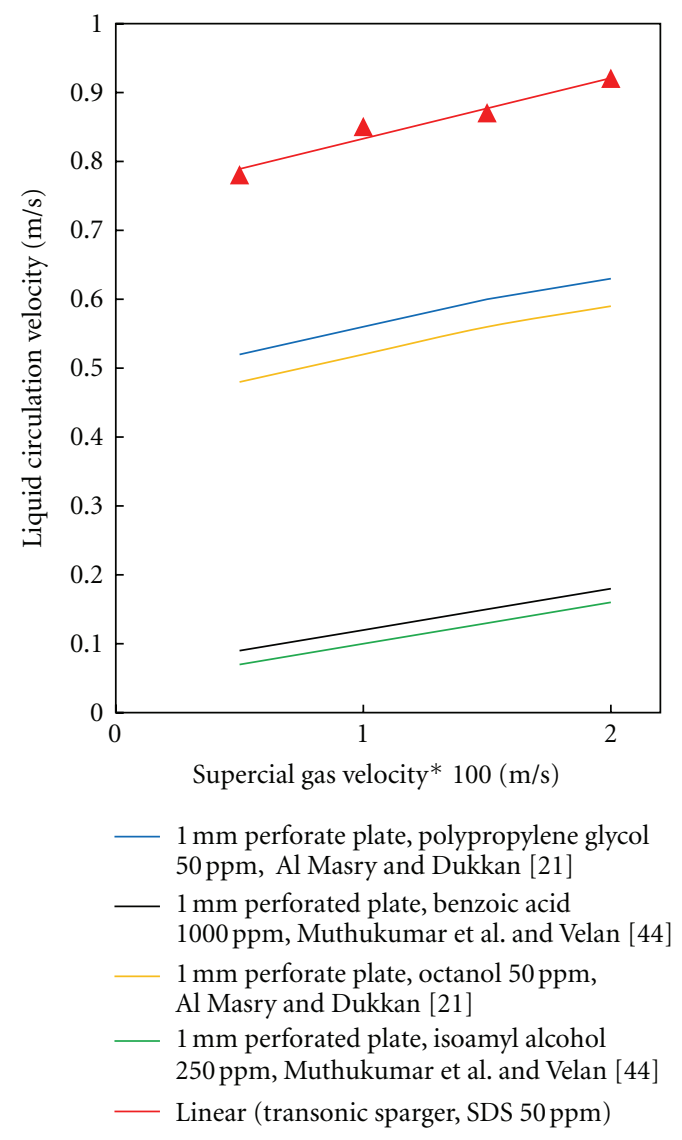

FIGURE 17: Effect of contaminants on liquid circulation velocity in $\operatorname{ALR}\left(C_{S}=50 \mathrm{ppm}, \Delta P_{S}=280 \mathrm{kPa}\right)$. recirculating stream with the consequent increase in the downcomer gas holdup and the reduction of the pressure differential between the riser and downcomer regions. This, in turn, adversely affected the motive force driving liquid circulation within the ALR. However, the liquid circulation velocities achieved in the presence of contaminants were about 8 -fold higher than those reported for the split ALR configuration where it is difficult to efficiently separate the fine bubbles formed in the presence of contaminants.

\section{Notation}

a: Specific interfacial area of contact between the phases $\left(\mathrm{m}^{2} / \mathrm{m}^{3}\right)$

$C_{S}: \quad$ Surfactant concentration, SDS (ppm)

$d_{32}: \quad$ Sauter mean bubble diameter $(\mu \mathrm{m})$

g: $\quad$ Acceleration of gravity $\left(\mathrm{m} \mathrm{s}^{-2}\right)$

$H_{\text {Riser }}$ : Height of the draft tube $(\mathrm{m})$

$k_{L}: \quad$ Liquid phase mass transfer coefficient $\left(\mathrm{m} \mathrm{s}^{-1}\right)$

$k_{L} a: \quad$ Volumetric mass transfer coefficient $\left(\mathrm{s}^{-1}\right)$

$\overline{P_{5}}: \quad$ Mean pressure at riser outlet $(\mathrm{Pa})$

$\overline{P_{4}}: \quad$ Mean pressure at the riser entrance $(\mathrm{Pa})$

$Q_{G}: \quad$ Gas volumetric flow rate $\left(\mathrm{m}^{3} \mathrm{~s}^{-1}\right)$

$Q_{L}: \quad$ Liquid volumetric flow rate $\left(\mathrm{m}^{3} \mathrm{~s}^{-1}\right)$

$T: \quad$ Absolute temperature in ${ }^{\circ} \mathrm{K}$

$t_{\text {Circ }}$ : Circulation time (s)

$U_{\text {Circ: }}$ Average liquid circulation velocity $\left(\mathrm{m} \mathrm{s}^{-1}\right)$

$U_{G}:$ Superficial gas velocity $\left(\mathrm{m} \mathrm{s}^{-1}\right)$

$W_{G}:$ Mass flow rate of gas fed to the sparger $\left(\mathrm{kg} \mathrm{s}^{-1}\right)$

$W_{L}$ : Mass flow rate of liquid fed to the sparger $\left(\mathrm{kg} \mathrm{s}^{-1}\right)$.

\section{Greek Symbols}
$\Delta P_{\text {Sparger }}:$ Pressure drop across the sparger $(\mathrm{Pa})$
$\mu: \quad$ Kinematic viscosity $\left(\mathrm{m}^{2} / \mathrm{s}\right)$
$\Phi_{\text {Riser }}: \quad$ Gas holdup (-)
$\sigma_{\infty}: \quad$ Static (equilibrium) surface tension $(\mathrm{m} \mathrm{N} / \mathrm{m})$
$\rho_{L}: \quad$ Liquid density $\left(\mathrm{kg} / \mathrm{m}^{3}\right)$.

\section{Acknowledgments}

The financial support of ACOA/BDP, NSERC, and Dalhousie University is gratefully acknowledged. The technical support of R. Dube, G. Jollimore, and J. Kozel is appreciated.

\section{References}

[1] M. Martín, F. J. Montes, and M. A. Galán, "Theoretical modelling of the effect of surface active species on the mass transfer rates in bubble column reactors," Chemical Engineering Journal, vol. 155, no. 1-2, pp. 272-284, 2009.

[2] G. Vázquez, G. Antorrena, and J. M. Navaza, "Influence of surfactant concentration and chain length on the absorption of $\mathrm{CO} 2$ by aqueous surfactant solutions in the presence and absence of induced Marangoni effect," Industrial and Engineering Chemistry Research, vol. 39, no. 4, pp. 1088-1094, 2000. 
[3] S. S. Alves, S. P. Orvalho, and J. M. T. Vasconcelos, "Effect of bubble contamination on rise velocity and mass transfer," Chemical Engineering Science, vol. 60, no. 1, pp. 1-9, 2005.

[4] E. Álvarez, D. Gómez-Díaz, J. M. Navaza, and B. Sanjurjo, "Continuous removal of carbon dioxide by absorption employing a bubble column," Chemical Engineering Journal, vol. 137, no. 2, pp. 251-256, 2008.

[5] D. Gómez-Díaz, J. M. Navaza, and B. Sanjurjo, "Gas-liquid interfacial area in the presence of different chain length surfactants," Industrial and Engineering Chemistry Research, vol. 48, no. 12, pp. 5894-5900, 2009.

[6] G. Hebrard, J. Zeng, and K. Loubiere, "Effect of surfactants on liquid side mass transfer coefficients: a new insight," Chemical Engineering Journal, vol. 148, no. 1, pp. 132-138, 2009.

[7] M. K. Moraveji, M. M. Pasand, R. Davarnejad, and Y. Chisti, "Effects of surfactants on hydrodynamics and mass transfer in a split-cylinder airlift reactor," The Canadian Journal of Chemical Engineering, vol. 90, no. 1, pp. 93-99, 2012.

[8] M. Jamnongwong, K. Loubiere, N. Dietrich, and G. Hébrard, "Experimental study of oxygen diffusion coefficients in clean water containing salt, glucose or surfactant: consequences on the liquid-side mass transfer coefficients," Chemical Engineering Journal, vol. 165, no. 3, pp. 758-768, 2010.

[9] M. Zlokarnik, "Tower-shaped reactors for aerobic biological waste water treatment," in Biotechnology, M. Zlokarnik and H. Brauer, Eds., pp. 537-69., 1985.

[10] A. M. Al Taweel and Y. H. Cheng, "Effect of surface tension on gas/liquid contacting in a mechanically-agitated tank with stator," Chemical Engineering Research and Design, vol. 73, no. 6, pp. 654-660, 1995.

[11] S. Bordel, R. Mato, and S. Villaverde, "Modeling of the evolution with length of bubble size distributions in bubble columns," Chemical Engineering Science, vol. 61, no. 11, pp. 3663-3673, 2006.

[12] K. Podila, A. M. Al Taweel, M. Koksal, A. Troshko, and Y. P. Gupta, "CFD simulation of gas-liquid contacting in tubular reactors," Chemical Engineering Science, vol. 62, no. 24, pp. 7151-7162, 2007.

[13] M. Miura and O. Vinogradov, "The effect of probability of coalescence on the evolution of bubble sizes in a turbulent pipeline flow: a numerical study," Computers and Chemical Engineering, vol. 32, no. 6, pp. 1257-1264, 2008.

[14] A. A. Mouza, G. K. Dalakoglou, and S. V. Paras, "Effect of liquid properties on the performance of bubble column reactors with fine pore spargers," Chemical Engineering Science, vol. 60, no. 5, pp. 1465-1475, 2005.

[15] J. H. J. Kluytmans, B. G. M. Van Wachem, B. F. M. Kuster, and J. C. Schouten, "Gas holdup in a slurry bubble column: influence of electrolyte and carbon particles," Industrial and Engineering Chemistry Research, vol. 40, no. 23, pp. 5326-5333, 2001.

[16] I. M. Šijački, M. S. Tokic, P. S. Kojic et al., "Sparger type influence on the hydrodynamics of the draft tube airlift reactor with diluted alcohol solutions," Industrial \& Engineering Chemistry Research, vol. 50, no. 6, pp. 3580-3591, 2011.

[17] J. F. Walter and H. W. Blanch, "Bubble break-up in gasliquid bioreactors: break-up in turbulent flows," The Chemical Engineering Journal, vol. 32, no. 1, pp. B7-B17, 1986.

[18] M. Asgharpour, M. R. Mehrnia, and N. Mostoufi, "Effect of surface contaminants on oxygen transfer in bubble column reactors," Biochemical Engineering Journal, vol. 49, no. 3, pp. 351-360, 2010.

[19] I. M. Šijački, R. R. Čolović, D. L. Petrović, M. N. Tekić, and M. S. Durić, "Diluted alcohol solutions in bubble columns and draft tube airlift reactors with a single orifice sparger: experiments and simple correlations," Journal of Chemical Technology and Biotechnology, vol. 85, no. 1, pp. 39-49, 2010.

[20] N. E. Azher, B. Gourich, C. Vial et al., "Influence of alcohol addition on gas hold-up, liquid circulation velocity and mass transfer coefficient in a split-rectangular airlift bioreactor," Biochemical Engineering Journal, vol. 23, no. 2, pp. 161-167, 2005.

[21] W. A. Al-Masry and A. R. Dukkan, "The role of gas disengagement and surface active agents on hydrodynamic and mass transfer characteristics of airlift reactors," Chemical Engineering Journal, vol. 65, no. 3, pp. 263-271, 1997.

[22] J. M. T. Vasconcelos, J. M. L. Rodrigues, S. C. P. Orvalho, S. S. Alves, R. L. Mendes, and A. Reis, "Effect of contaminants on mass transfer coefficients in bubble column and airlift contactors," Chemical Engineering Science, vol. 58, no. 8, pp. 1431-1440, 2003.

[23] K. C. Ruthiya, J. Van Der Schaaf, B. F. M. Kuster, and J. C. Schouten, "Influence of particles and electrolyte on gas holdup and mass transfer in a slurry bubble column," International Journal of Chemical Reactor Engineering, vol. 4, pp. 1-37, 2006.

[24] M. D. Bredwell and R. M. Worden, "Mass-transfer properties of microbubbles. 1. Experimental studies," Biotechnology Progress, vol. 14, no. 1, pp. 31-38, 1998.

[25] K. Yasuda, Y. Wang, K. Haneda et al., "Development of airlift bubble column dispersed with micro-bubbles," Canadian Journal of Chemical Engineering, vol. 88, no. 4, pp. 518-522, 2010.

[26] M. K. H. Al-Mashhadani, H. C. H. Bandulasena, and W. B. Zimmerman, " $\mathrm{CO}_{2}$ mass transfer induced through an airlift loop by a microbubble cloud generated by fluidic oscillation," Industrial \& Engineering Chemistry Research, vol. 51, no. 4, pp. 1864-1877, 2012.

[27] W. B. Zimmerman, B. N. Hewakandamby, V. Tesar, H. C. H. Bandulasena, and O. A. Omotowa, "On the design and simulation of an airlift loop bioreactor with microbubble generation by fluidic oscillation," Food and Bioproducts Processing C, vol. 87, no. 3, pp. 215-227, 2009.

[28] Y. Bando, T. Yoshimatsui, W. Luo et al., "Flow characteristics in cocurrent upflow bubble column dispersed with microbubbles," Journal of Chemical Engineering of Japan, vol. 41, no. 7, pp. 562-567, 2008.

[29] Y. Bando, T. Yoshimatsu, Y. Wang, K. Yasuda, T. Sugie, and T. Asai, "Influence of micro-bubble on ozone-decomposition of excess sludge," Japanese Journal of Multiphase Flow, vol. 3, pp. 51-57, 2008.

[30] L. B. Chu, X. H. Xing, A. F. Yu, X. L. Sun, and B. Jurcik, "Enhanced treatment of practical textile wastewater by microbubble ozonation," Process Safety and Environmental Protection, vol. 86, no. 5, pp. 389-393, 2008.

[31] C. Vial, S. Poncin, G. Wild, and N. Midoux, "A simple method for regime identification and flow characterisation in bubble columns and airlift reactors," Chemical Engineering and Processing, vol. 40, no. 2, pp. 135-151, 2001.

[32] B. Gourich, C. Vial, A. H. Essadki, F. Allam, M. B. Soulami, and M. Ziyad, "Identification of flow regimes and transition points in a bubble column through analysis of differential pressure signal-influence of the coalescence behavior of the liquid phase," Chemical Engineering and Processing, vol. 45, no. 3, pp. 214-223, 2006.

[33] A. M. Al Taweel, J. J. Luo, and J. Wang, "Dynamic spargers: a novel approach to intensifying gas/liquid contacting operations," in Proceedings of the 5th International Process 
Intensification Conference, A. Stankiewicz, Ed., pp. 91-106, BHR, Cranfield, UK, 2003.

[34] H. Kawashima, A. Figiwara, Y. Saitoh, K. Hishidah, and Y. Kodama, "Experimental study of drag reduction by microbubble: laser measurements and microbubble generator," in Proceedings of the 6th Symposium on Smart Control of Turbulence, Tokyo, Japan, March 2005.

[35] A. Stankiewicz, "Process-intensification: a European perspective," in Proceedings of the 6th International Conference on Process Intensification, Delft, The Netherlands, 2006.

[36] A. M. Al Taweel, A. M. Ramadan, M. R. Moharam, S. M. El Mofty, and M. T. Ityokumbul, "Effect of honeycomb inserts on axial mixing in bubble columns," Chemical Engineering Research and Design, vol. 74, no. 4, pp. 456-462, 1996.

[37] A. M. Al Taweel, A. Idhbeaa, and A. Ghanem, "Effect of electrolytes on inter-phase mass transfer in microbubblesparged airlift reactors," in Proceedings of the 9th World Congress of Chemical Engineering (WCCE'09), Seoul, Republic of Korea, August 2013.

[38] R. S. Nicol and J. F. Davidson, "Effect of surfactants on the gas hold-up in circulating bubble columns," Chemical Engineering Research and Design, vol. 66, no. 2, pp. 159-164, 1988.

[39] J. B. Snape, J. Zahradník, M. Fialová, and N. H. Thomas, "Liquid-phase properties and sparger design effects in an external-loop airlift reactor," Chemical Engineering Science, vol. 50, no. 20, pp. 3175-3186, 1995.

[40] J. C. Merchuk, A. Contreras, F. García, and E. Molina, "Studies of mixing in a concentric tube airlift bioreactor with different spargers," Chemical Engineering Science, vol. 53, no. 4, pp. 709719, 1998.

[41] B. R. Poulsen and J. J. L. Iversen, "Membrane sparger in bubble column, airlift, and combined membrane-ring sparger bioreactors," Biotechnology and Bioengineering, vol. 64, no. 4, pp. 452-458, 1999.

[42] C. Cao, S. Dong, Q. Geng, and Q. Guo, "Hydrodynamics and axial dispersion in a gas-liquid-(solid) EL-ALR with different sparger designs," Industrial and Engineering Chemistry Research, vol. 47, no. 11, pp. 4008-4017, 2008.

[43] S. Wachi, A. G. Jones, and T. P. Elson, "Flow dynamics in a draft-tube bubble column using various liquids," Chemical Engineering Science, vol. 46, no. 2, pp. 657-663, 1991.

[44] K. Muthukumar and M. Velan, "Influence of additives and geometric design on hydrodynamic characteristics of an internal loop airlift reactor," Journal of Chemical Engineering of Japan, vol. 38, no. 4, pp. 253-263, 2005.

[45] M. Y. Chisti and M. Moo-Young, "Hydrodynamics and oxygen mass transfer in a pneumatic bioreactor devices," Biotechnology and Bioengineering, vol. 31, no. 5, pp. 487-494, 1988.

[46] C. Bentifraouine, C. Xuereb, and J. P. Riba, "Effect of gas liquid separator and liquid height on the global hydrodynamic parameters of an external loop airlift contactor," Chemical Engineering Journal, vol. 66, no. 2, pp. 91-95, 1997.

[47] M. Gavrilescu and R. Z. Tudose, "Concentric-tube airlift bioreactors. Part I: effects of geometry on gas holdup," Bioprocess Engineering, vol. 19, no. 1, pp. 37-44, 1998.

[48] J. C. Merchuk, "Airlift bioreactors: review of recent advances," Canadian Journal of Chemical Engineering, vol. 81, no. 3-4, pp. 324-337, 2003.

[49] W. A. Al-Masry, "Effects of antifoam and scale-up on operation of bioreactors," Chemical Engineering and Processing, vol. 38, no. 3, pp. 197-201, 1999.
[50] H. Tsuge, S. Otatsume, K. Kobayashi, K. Terasaka, M. Hayasaki, and H. Kobayashi, "Liquid circulation and mass transfer in an external-loop airlift reactor with partitioning plates," Journal of Chemical Engineering of Japan, vol. 37, no. 8, pp. 941-946, 2004. 

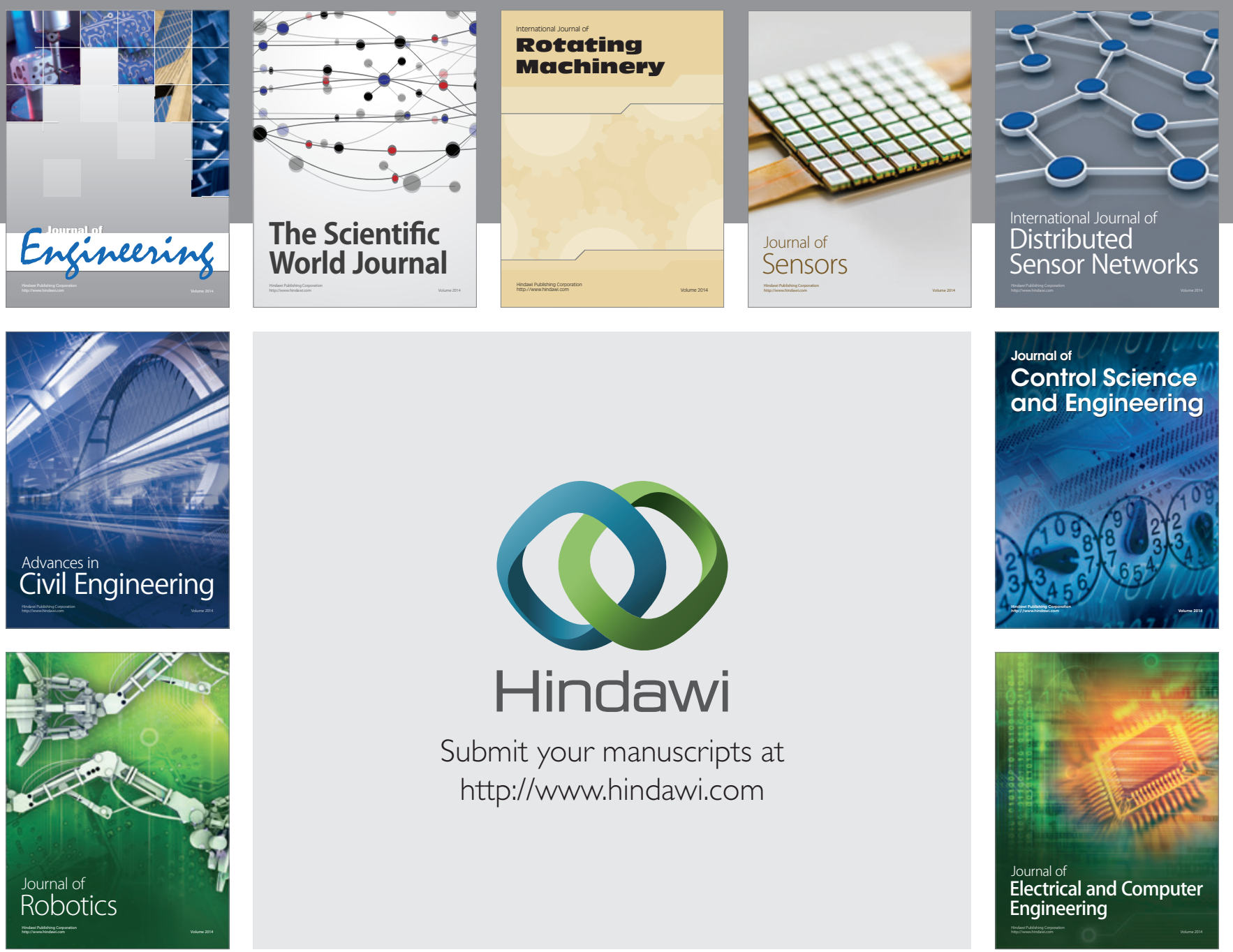

Submit your manuscripts at

http://www.hindawi.com
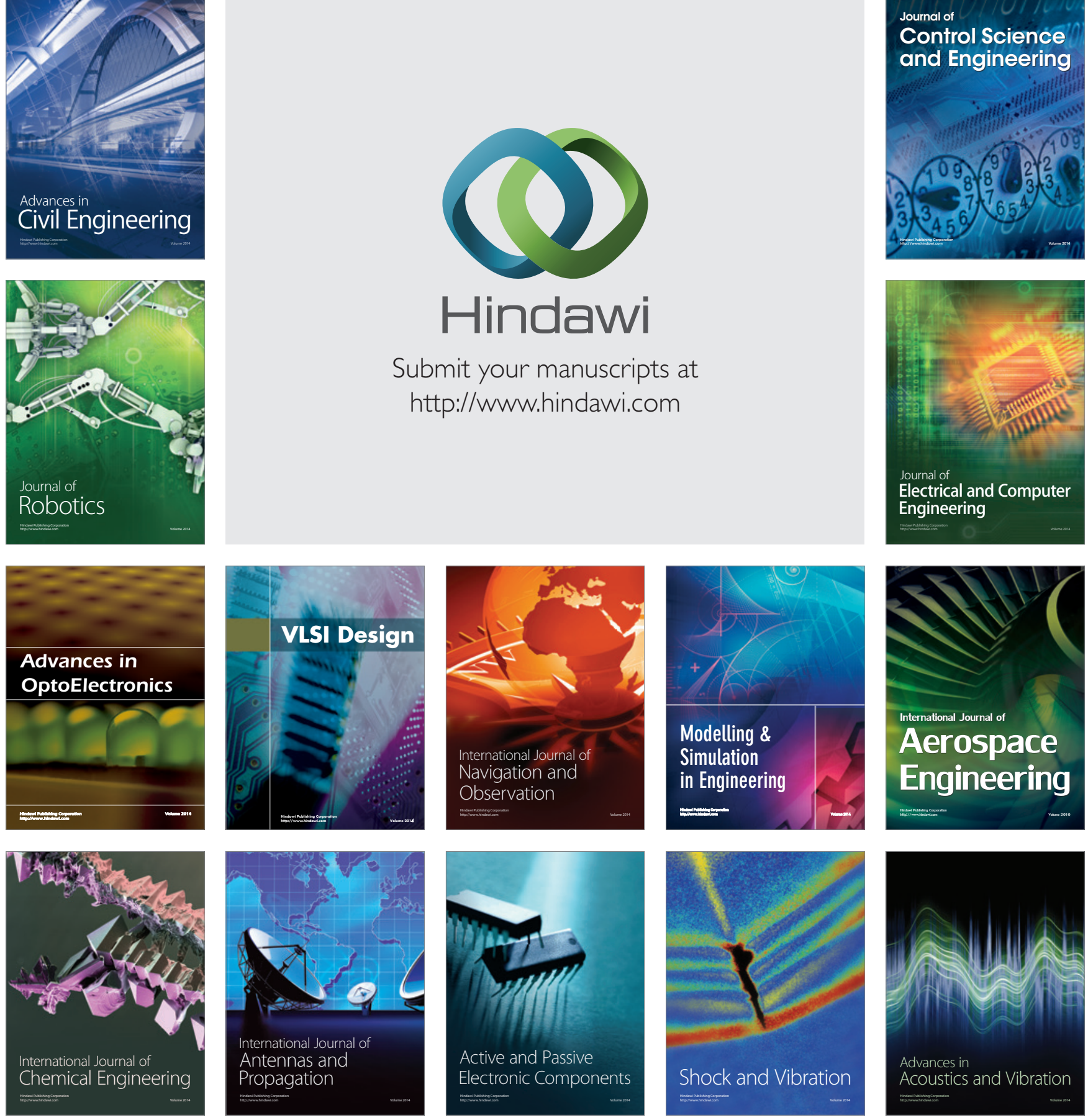